\title{
LA PROTECCIÓN PENAL DEL/DE LA MENOR VÍCTIMA DE DELITOS. HACIA UN DERECHO PENAL BASADO EN EL PARADIGMA DE LA VICTIMOLOGÍA EVOLUTIVA Y LA VULNERABILIDAD DEL/LA MENOR DE EDAD ${ }^{1}$
}

\author{
Ana I. Pérez Machío \\ Profa. Titular (Catedrática acreditada) Derecho Penal UPV/EHU \\ Instituto Vasco de Criminología/Kriminologiaren Euskal Institutua \\ Title: Criminal Law protections for victims under the age of 18. Towards a \\ Criminal Law based on the paradygm of Developmental Victimology and the \\ child's vulnerability.
}

Resumen: A partir de los postulados de la "Victimología Evolutiva", el presente artículo pretende abordar la realidad de la tutela penal reformada de la minoría de edad en su condición de víctima de delitos. La esquizofrenia legislativa, existente en esta materia, en el marco del Código Penal español, evidencia una deriva muy alejada del paradigma de la "Victimología Evolutiva" que permite comprender la victimización de menores de edad, y el diferente tratamiento, también jurídico-penal a adoptar en esos supuestos.

Palabras clave: Minoría de edad; víctima de delitos; Victimología Evolutiva; vulnerabilidad.

Abstract: From the postulates of "Developmental Victimology", this article aims to address the reality of the reformed criminal protection of the minority of age as a victim of crimes. Legislative schizophrenia, existing in this area, within the framework of the Spanish Penal Code, shows a drift far removed from the paradigm of "Developmental Victimology" that allows

1 El presente trabajo se ubica en el marco del proyecto de investigación "La integración social del/de la menor víctima a partir de una tutela penal reforzada" (DER 201783329-R) y en el Grupo Consolidados GICCAS/Grupo de Investigación en Ciencias Criminológicas. Gobierno Vasco (Grupo Consolidados IT 1372-19) 
to understand the victimization of minors, and the different treatment, also legal-penal to be adopted in such cases.

Keywords: Age minority; victim of crime; Developmental Victimology; vulnerability.

Sumario: 1. Introducción. - 2. El paradigma de la victimología evolutiva (o del desarrollo) como pilar de una especial protección de la persona menor de edad en cuanto víctima de delito. - 2.1. Vulnerabilidad de la persona menor de edad víctima como riesgo de victimización. - 2.2. Aproximación al riesgo de victimización de los/as menores de edad a partir de los postulados de la Victimología del desarrollo. - 2.3. Síntesis. - 3. Respuestas jurídico internacionales: hacia una protección y tutela reforzada de los/as menores de edad víctimas de delitos. - 3.1. Aproximación a los instrumentos internacionales más significativos de tutela de las personas menores víctimas. - 3.2. Especial protección de los menores de edad víctimas de delitos desde el punto de vista internacional. Hacia una tutela reforzada del/a menor víctima, sustentada en su grado de madurez y desarrollo. - 4. Especial protección del menor de edad en el ámbito del ordenamiento jurídico español. - 4.1. Penas de inhabilitación para el ejercicio de la patria potestad, guarda y custodia de los menores. - 4.2. Penas que suponen alejamiento de menores. - 4.3. Incidencia de la minoría de edad en la parte especial del Código. - 4.3.1. Introducción. - 4.3.2. Aproximación a los tipos delictivos de tutela penal reforzada cuando el sujeto pasivo es una víctima menor de edad. - 5. A modo de conclusión. La tutela penal reforzada del/de la menor víctima en el código penal: de un derecho penal moralizante hacia un derecho penal basado en el paradigma de la victimología evolutiva y la vulnerabilidad del menor de edad. - Bibliografía.

\section{Introducción ${ }^{2}$}

La tradición jurídico-penal ha sido proclive a la agravación de las penas en aquellos tipos delictivos en los que el sujeto pasivo era un menor de edad. La técnica utilizada por el legislador penal ha venido variando, en función de la propia naturaleza y esencia del delito. En algunos supuestos, se ha optado por el incremento del marco punitivo, configurando diversas modalidades de tipos agravados, respecto de delitos, cuyo tipo básico acoge como sujeto pasivo a cualquier persona ${ }^{3}$ $\mathrm{y}$, en otras ocasiones, la respuesta punitiva evidencia la presencia de delitos graves, cuyo tipo básico se configura directamente sobre la base de la existencia de un sujeto pasivo en el que concurre la circunstancia de la minoría de edad ${ }^{4}$.

2 Agradezco a la estudiante del Grado en Derecho UPV/EHU Alicia Buendía su colaboración en la elaboración del presente artículo.

3 A modo de ejemplo, véase dicha técnica legislativa en el artículo 140.1.1. CP, en el marco de los delitos contra la vida, cuando destaca lo siguiente: “1. El asesinato será castigado con pena de prisión permanente revisable cuando concurra alguna de las siguientes circunstancias:

1. Que la víctima sea menor de 16 años de edad, o se trate de una persona especialmente vulnerable por razón de su edad, enfermedad o discapacidad [...]".

4 Téngase en cuenta los delitos contemplados en el Capítulo II bis del Código Penal, que responden a la siguiente rúbrica: "De los abusos y agresiones sexuales a menores de 16 años". 
En todos los supuestos la circunstancia de la minoría de edad ha venido siendo concebida como una manifestación de la "vulnerabilidad" que concurre en el sujeto pasivo menor de edad ${ }^{5}$. Ahora bien, siendo la vulnerabilidad del menor de edad la razón última que permite la configuración de marcos punitivos graves, la cuestión a tener en cuenta reside en las razones tanto victimológicas, como jurídico-penales que configuran el rasgo de la vulnerabilidad de las personas menores de edad, a la vista, tanto de la amplitud extensiva de la etapa considerada como "minoría de edad" (hasta los 18 años -criterio cronológico puro-), como del propio desarrollo de la madurez o capacidad de discernimiento de los/as menores.

Una aproximación a la totalidad de las circunstancias que configuran la vulnerabilidad en la minoría de edad de la víctima, desde un plano tanto victimológico, como jurídico-penal, permitirá discernir si la respuesta dada, en estos supuestos, por el Código Penal español responde directamente a la existencia de una necesidad de tutela reforzada o es fruto de una decisión político-criminal específica.

\section{El paradigma de la victimología evolutiva (o del desarrollo) como pilar de una especial protección de la persona menor de edad en cuanto víctima de delito}

\subsection{Vulnerabilidad de la persona menor de edad víctima como riesgo de victimización}

En el sentido apuntado anteriormente, el mayor condicionante que determina la victimización de las personas menores de edad reside, fundamentalmente, en su vulnerabilidad.

En efecto, como viene considerando mayoritariamente la doctrina, la especial protección de las personas menores de edad víctimas de delitos se configura sobre la base de su vulnerabilidad, asociada a la falta de madurez propia de esta etapa vital, según sus características biológicas, psicológicas y socioculturales ${ }^{6}$. Es lo que González Agudelo viene denominando como "vulnerabilidad subjetiva", en atención a las

5 Por todos, De Los SANTOS FARINATI, "Consideraciones sobre el maltrato a la infancia”, p. 269; GRACIA FUSTER, Las víctimas invisibles de la violencia familiar, p. 26; HERRERO Moreno, La hora de la víctima, p. 206; LANDRove DíAz, La moderna Victimología, p. 47; Martínez Roig, "Factores de vulnerabilidad infantil”, p. 75; Morillas Fernández/Patró Hernández/Aguilar CÁRceles, Victimología: un estudio sobre la víctima, p. 207.

6 Por todos, Andreu Fernández, "Menores víctimas y situaciones de victimización”, p. 61; GonZÁlez Agudelo, "El menor como víctima del delito”, p. 271, entre otros. 
circunstancias personales ${ }^{7}$ que hacen incrementar el riesgo de victimización ${ }^{8}$. En el supuesto de las personas menores de edad víctimas de delitos la "vulnerabilidad subjetiva" refleja los supuestos de inferioridad e indefensión victimal en los que se encuentran los/as menores, sustentados sobre la base de las características biológicas y psicológicas que concurren en los/as mismos/as.

Así, cuanta menos edad tenga la persona, menor desarrollo biológico, y a mayor edad, mayor desarrollo, pudiendo, en las distintas tipologías delictivas, en las que existen diferencias significativas en cuanto a grupos de edad, aislarse fácilmente un grupo de especial vulnerabilidad, por su escaso desarrollo biológico ${ }^{9}$. Como muy acertadamente destaca Herrera Moreno aquellos individuos más vulnerables por la falta de desarrollo de sus facultades físicas y psíquicas devienen blancos idóneos de victimización violenta y, más concretamente, de particulares manifestaciones delictivas relacionadas con dicha inferioridad biológica, como, por ejemplo, el maltrato infantil ${ }^{10}$.

Sobre el desarrollo biológico y el nivel de madurez y la capacidad de discernimiento de los menores de edad, desde la perspectiva de la incapacidad de generar contextos de autoprotección y autodefensa, podemos traer a colación la interpretación doctrinal que permite sustentar, desde el punto de vista de los/as menores infractores, la incapacidad de discernimiento y de comprensión de los/as menores de 14 años que les sitúa en el ámbito de la inimputabilidad penal.

En efecto, existe la convicción de que el menor de 14 años presenta un desarrollo físico y psicológico sumamente incompleto ${ }^{11}$ que fundamenta la inimputabilidad de los $\operatorname{mismos}{ }^{12}$, en cuanto no tienen capacidad de culpabilidad ${ }^{13}$. Consecuentemente los supuestos en los que un menor de 14 años cometa un ilícito penal serán sometidos a la normativa sobre protección de menores. Así lo destaca Vázquez González, cuando apunta que, en todos estos supuestos, se entiende que el grado de inmadurez de los/as niños/as, determina la necesidad de que queden fuera no sólo del Derecho Penal, sino de cualquier intervención del aparato judicial sancionador del Estado, siendo suficiente una respuesta de los servicios sociales ${ }^{14}$.

Véase, GonzÁlez Agudelo, "El menor como víctima del delito”, p. 272.

8 Herrera Moreno, La hora de la víctima, p. 205.

9 Morillas Fernández/Patró Hernández/Aguilar CÁrceles, Victimología, p. 210.

10 En este sentido, Herrera Moreno, La hora de la víctima, p. 206.

11 Por todos, Higuera Guimerá, Derecho Penal juvenil, p. 308.

12 En este sentido, VÁzQuez González, Delincuencia juvenil, p. 207.

13 Pérez Machío, El tratamiento jurídico-penal de los menores infractores, p. 42.

14 VÁzouez González, Delincuencia juvenil, p. 233. En idéntico sentido, Dolz Lago, La nueva responsabilidad penal del menor, p. 44. 
Desde esta perspectiva, habida cuenta del grado de inmadurez que los/as menores de 14 años presentan, hasta dicha edad, existe una presunción de absoluta inimputabilidad. La inmadurez entendida como un estado físico, psicológico e incluso social que les impide la comprensión no sólo de los actos cometidos ${ }^{15}$, sino de los postulados de las normas en las que se apoyan las disposiciones legales, determina el principio de irresponsabilidad penal de los/as mismos, caracterizado por el recurso, en estos casos, a medidas educativas que refuercen el proceso de desarrollo personal y de discernimiento en el que se encuentran inmersos/as.

Con este criterio cronológico, a partir de una determinada edad (14 años) existe una presunción de capacidad mínima de comprensión del ilícito penal y de actuar conforme a él, es decir, disponen de una cierta autonomía más o menos desarrollada en función de su edad y de su desarrollo físico y psicológico de donde parece desprenderse su responsabilidad de manera automática, prescindiendo de las concepciones sobre las que se basa la responsabilidad de los adultos ${ }^{16}$, esto es, de las personas mayores de 18 años.

Así, si el fundamento de una respuesta punitiva diferente en los supuestos de infractores entre 14 y 18 años, así como de una respuesta meramente educativa en los casos de personas menores de 14 años encuentra su fundamento en el grado de inmadurez personal de este colectivo de sujetos, sobre idéntico sustrato pivota la idea de "vulnerabilidad subjetiva" de los menores de edad, en tanto que víctimas de delitos.

La incapacidad de discernimiento suficiente desde el punto de vista intelectual, volitivo y de asimilación de representaciones o de valores se configura, por lo tanto, como una característica intrínseca a todas aquellas personas menores de edad, ubicándolas en un estadio biológico, físico y psicológico de inferioridad de indefensión, propios del concepto de "vulnerabilidad subjetiva" ahora manejado.

Así las personas menores de edad, en general, devienen blancos idóneos de victimización violenta, en tanto que individuos más vulnerables por la falta de desarrollo de sus facultades físicas y psíquicas relacionadas con su inferioridad biológica y psicosocial.

Ahora bien, junto a la vulnerabilidad subjetiva pueden darse igualmente supuestos de vulnerabilidad del menor delimitados por las interacciones con el entorno (situacional) que presentan características propias, esto es, niños/as que viven en determinadas condiciones de pobreza, de marginalidad, de desestructuración familiar, de abandono ${ }^{17}$. En estos

15 Higuera Guimerá, Derecho Penal juvenil, p. 115.

16 OtTnehof, "La responsabilidad penal de los menores", p. 6. Igualmente, PÉrez MAcHío, El tratamiento jurídico-penal de los menores infractores, p. 46.

17 GonzÁlez Agudelo, "El menor como víctima del delito", p. 272. 
contextos, los condicionantes sociales del núcleo familiar van a predisponer a todos los integrantes a una situación de vulnerabilidad no deseada. La dependencia emocional, educativa, cultural, económica, alimentaria e higiénica, entre otras, que los/as niños/as tienen con sus familias se verá satisfecha en relación a las posibilidades humanas, educacionales y económicas del grupo familiar ${ }^{18}$. Hay pues que incluir como factores de vulnerabilidad infantil, los estructurales por defecto como serían la falta de empleo, la falta de relación personal, el poco cultivo de los valores espirituales o la escasa formación humana y cultural; pero también los estructurales por exceso, como pueden ser la posesión de abundantes bienes materiales difíciles de administrar, el exceso de trabajo que repercute en la calidad de vida, el exceso de vida social que olvida el núcleo familiar o el consumismo y competitividad mal aplicada ${ }^{19}$.

La vulnerabilidad social o situacional incrementa igualmente el riesgo de victimización de los/as menores de edad, en tanto que genera, en muchas ocasiones, una doble victimización: la propia del delito que se comete sobre el menor, a la vista del contexto de indefensión y de desprotección en el que se encuentra, desde un punto de vista subjetivo, y la generada como consecuencia de los factores situacionales ahora mencionados.

Desde esta perspectiva, la propensión victimal del/a menor de edad hacia la victimización opera sobre la base de su "vulnerabilidad subjetiva y situacional", esto es, existe un elenco de factores de riesgo personales (falta de desarrollo del mismo) y situacionales (pertenencia a un grupo discriminado) que, en cuanto concurren en la persona del menor de edad, devienen blancos idóneos de victimización violenta y más concretamente de particulares manifestaciones delictivas, relacionadas con dicha inferioridad, como puede ser el maltrato infantil o el abuso ${ }^{20}$.

\subsection{Aproximación al riesgo de victimización de los/as menores de edad a partir de los postulados de la Victimología del desarrollo}

El abordaje victimológico de la realidad de la victimización de los menores de edad, debe incorporar una perspectiva evolutiva del riesgo, en tanto que los tipos de victimizaciones dependen básicamente de la

18 Como destaca GonZÁlez Agudelo, “El menor como víctima del delito”, p. 280, Los adultos pueden elegir sus propias compañías, sin embargo, el grado de dependencia de los menores de edad limita dicha capacidad: no eligen a su familia, tampoco el entorno en el que se relacionan (barrio, escuela), todo ello explica su condición de potencial víctima de delitos.

19 Martínez Roig, "Factores de vulnerabilidad infantil”, p. 78.

20 Herrera Moreno, La hora de la víctima, 206. 
edad y del grado del desarrollo del menor ${ }^{21}$. Son los postulados de la Victimología del desarrollo que entiende que la victimización de menores pivota sobre dos pilares: por un lado, el mayor riesgo de victimización que caracteriza a este colectivo y, por otro, la capacidad del infante de afrontar la situación traumática experimentada.

Por lo que respecta al primero de los elementos, esto es, un potencialmente mayor riesgo de victimización, además de su posición de dependencia, las víctimas menores suelen caracterizarse por elevados o totales niveles de inconsciencia respecto a la victimización, lo que las convierte en víctimas ideales, aspecto que tendrá importantes implicaciones en las consecuencias psicológicas y sociales que puedan derivarse ${ }^{22}$. Cabe añadir que su debilidad física, su menor tamaño, su falta de autonomía y su total confianza en el adulto, han favorecido que la victimización infanto-juvenil sea más frecuente que lo que inicialmente podría estimarse y existe una preocupación cada vez más insistente sobre la infancia y su calidad de vida ${ }^{23}$, en tanto que grupo de edad más vulnerable en el ámbito victimológico ${ }^{24}$.

En efecto, los niños más jóvenes forman un grupo de alto riesgo porque son pequeños e inmaduros físicamente y tienen dificultades a la hora de huir de sus agresores o de protegerse ${ }^{25}$. Desde esta perspectiva, la Victimología del desarrollo o evolutiva defiende que niños y niñas sufren las mismas victimizaciones que los adultos, pero, al mismo tiempo, se encuentran en una posición de mayor riesgo para la vivencia directa o indirecta de muchas otras victimizaciones vinculadas, principalmente, a su nivel de dependencia y a su inmadurez, lo que les ubica en una situación de especial vulnerabilidad.

En cuanto al segundo de los elementos que delimitan la victimización de menores de edad, esto es su capacidad de afrontar la situación traumática experimentada, la etapa del desarrollo en la que se sufra la situación de victimización, así como las características personales del menor de edad, condicionarán, en opinión de Morillas Fernández, Patró Hernández y Aguilar Cárceles, una mayor o menor vulnerabilidad a desarrollar secuelas crónicas o trastornos psicopatológicos a lo largo del tiempo que podrían acontecer, incluso en la etapa adulta, cuando los factores de protección del menor resultaran insuficientes ${ }^{26}$. Así, es común que la población infanto-juvenil se vea expuesta a los mismos tipos de victimización que los adultos. Sin embargo, se encuentran en

21 FilKenhor, "Factores de riesgo", p. 170.

22 En este sentido, Gamboa De Trejo, "Víctimas de la violencia”, p. 6.

23 Pereda/Abad/Guilera, Victimología del desarrollo, p. 15.

24 Pereda/Abad/Guilera, Victimología del desarrollo, p. 14.

25 FilKenHor, "Factores de riesgo", p. 171.

26 Véanse, en este sentido, Morillas Fernández/Patró Hernández/Aguilar Cárceles, Victimología, p. 473. 
una posición de riesgo más alto de desarrollar consecuencias negativas a largo plazo. Esto es debido a que durante su crecimiento están inmersos en un proceso de desarrollo afectivo, cognitivo y social en el que cualquier evento adverso puede generar un impacto en el resultado final de dicho proceso, afectando con ellos sus recursos individuales, el desarrollo de habilidades y/o destrezas futuras ${ }^{27}$. Así, hay estudios que evidencian que las victimizaciones que se inician en la infancia, las provoca alguien del entorno habitual ${ }^{28}$ y tienen un efecto negativo en el estado emocional del menor que puede afectar a su desarrollo ${ }^{29}$. De hecho, se insiste en que hay una alta frecuencia de estos casos entre la población infantil y adolescente que confirma que la acumulación de experiencias victimizantes puede provocar niveles más elevados de psicopatología general ${ }^{30}$, así como de sintomatología internalizante y externalizante en los menores polivictimizados ${ }^{31}$.

La Victimología evolutiva o del desarrollo contribuye, en última instancia, a hacer visibles a los menores víctimas, mostrarlos no como meros espectadores, sino como víctimas que, según destacan Abad, Pereda y Guilera, se ven privadas de derechos y libertades básicos para su correcto desarrollo ${ }^{32}$. Algunos niños y niñas son víctimas de múltiples experiencias de violencia o polivíctimas, configurándose la experiencia de violencia para estos menores más como una condición vital permanente que como un acontecimiento puntual en sus vidas ${ }^{33}$, en la medida en que supone un elevado riesgo de desajustes en el desarrollo normal del adolescente ${ }^{34}$.

En línea con la perspectiva de la victimología del desarrollo, no todas las formas de victimización se inician a las mismas edades, ni se producen con igual frecuencia en chicos y chicas, lo que debería permitir establecer períodos y grupos de riesgo para victimizaciones específicas a partir del análisis del momento de inicio y la frecuencia según el sexo de los diferentes tipos de victimización. Es importante destacar, siguiendo a la doctrina mayoritaria, que la mayoría de las victimizaciones se inician o bien durante la infancia (hasta los 10-12 años) ${ }^{35}$ o bien durante

\footnotetext{
27 Así, Pinto Cortéz/Venegas Sanhueza, “Experiencias de victimización”, p. 6.

28 En esta etapa se ubicarían lo que FILKENHOR, "Factores de riesgo", p.162 denomina como victimizaciones agudas, que les sucede a un número mayor de niños/as, destacando los maltratos físicos, el abandono o negligencia y el abuso sexual.

29 Así, Pereda/Guilera/Abad, "Victimización infanto-juvenil en España”, p. 66 y ss.

30 En este sentido, PEREDA, "Menores víctimas de terrorismo", pp. 14 y ss.

31 Véase, el estudio de PEREDA/ABAd/GuilerA, "Victimología del desarrollo", pp. 1 y ss.

32 ABAd/Pereda/Guilera, "La exposición de los menores españoles a la violencia familiar", p. 1.

33 Pereda/Abad/Guilera, "Victimología del desarrollo", p. 2.

34 Pereda/Abad/Guilera, "Victimología del desarrollo", p. 4.

35 Algunos autores como Puyol Wilson/Salinas CHAud, "Agresiones sexuales infantojuveniles", p. 267, apunta a un promedio de edad entre 6 y 8 años. En idéntico sentido se ubican otros trabajos empíricos que, en relación al abuso sexual, destacan que el abuso
} 
los primeros años de la adolescencia (12-13) y que muy pocas ocasiones después de los 13 años ${ }^{36}$.

Atendiendo al tipo de acontecimientos, durante la infancia se inician la mayoría de las victimizaciones relacionadas con el entorno más cercano del menor ${ }^{37}$, pero también las agresiones por iguales. Así, en las fases tempranas de su vida la violencia contra el niño es fundamentalmente intrafamiliar y, conforme la edad y el conocimiento aumentan, la violencia intrafamiliar disminuye y crece la violencia ejercida por extraños, proceso que culmina en la adolescencia tardía ${ }^{38}$. Es interesante poner de manifiesto que durante la infancia la única victimización sexual presente es la que tiene lugar a manos de adultos $\operatorname{conocidos}^{39}$.

A modo de ejemplo, según destacan Morillas Fernández, Patró Hernández y Aguilar Cárceles, el/la niño/a es una víctima propicia en el ámbito de la violencia doméstica. Si bien no resulta una tarea sencilla, continúan, concretar un perfil específico del/a menor con mayor probabilidad de ser victimizado, existen algunos factores precipitantes y predisponentes que precipitan el desarrollo del comportamiento de maltrato en niños/as con mayor vulnerabilidad, incorporándose en este colectivo, en mayor medida, aquellos que contemplan características referidas a la edad del menor, puesto que el período más comúnmente de maltrato al menor es, según estos autores, el comprendido desde su nacimiento hasta los tres años, a la vista de la indefensión que presenta este colectivo. En efecto, el recién nacido no cuenta con medios propios de protección, continúan los mismos, por lo que el victimario podrá realizar libremente todos los actos violentos que desee. A sensu contrario, a medida que va creciendo el/la menor adquiere más instrumentos de defensa frente a las agresiones del victimario, esto es, la reiteración de ataques de especial relevancia puede despertar sospechas en los centros hospitalarios; la fortaleza física de la víctima, que aumenta año tras año, impedirá al

sexual en niñas se presenta en edades tempranas, esto es, de 4 a 6 años, y en el supuesto de los niños dicho rango de edad oscila entre los 7 y los 15 años, debiendo destacarse la mayor incidencia que este fenómeno delictivo presenta en las niñas que en los niños. Así lo recoge Bladés PACHECo, "Caracterización victimológica ligada al proceso de denuncia en víctimas de abuso sexual infantil”, p. 5.

36 PeredA/Abad/Guilera, "Victimología del desarrollo", p. 93.

37 Especialmente destacable en los supuestos de agresiones y abusos sexuales, esto es, atentados contra la indemnidad sexual de los menores, donde se revela como especialmente destacable el vínculo intrafamiliar entre víctima y victimario, muy frecuente en estos fenómenos delictivos en los que destaca la vulnerabilidad y el sometimiento de la víctima. Así lo apuntan Puyol Wilson/Salinas CHaud, "Agresiones sexuales infanto-juveniles", p. 268.

38 FilKenhor, "Factores de riesgo", p. 171.

39 Como destaca Filkenhor, "Factores de riesgo", p. 172, en las fases tempranas del desarrollo, los niños y niñas tienen riesgos y patrones de victimización parecidos. Sin embargo, continúa el autor, cuando crecen, los chicos empiezan a sufrir más homicidios y las chicas más ataques sexuales. 
maltratador ejercer violencia contra el/la menor; su círculo de amistades puede ayudarle a denunciar los hechos o darle refugio; el agresor es consciente de que conforme avanzan los años, dicha violencia puede volverse contra él; en definitiva, una serie de mecanismos de defensaataque desarrollados con el paso del tiempo e inexistentes al principio, limitadores del poder ejercido por el sujeto activo durante los primeros años de agresiones ${ }^{40}$.

En la adolescencia aparecen nuevos tipos de victimización, la mayoría fuera de este ámbito más cercano. Por lo tanto, una buena parte de la victimización en menores, especialmente en la infancia, suele ser cometida, por personas adultas del entorno más cercano. Además, es preciso tener en cuenta que la victimización por cuidadores/as acostumbra a tener un carácter más recurrente que la mayoría de acontecimientos. Este hecho muestra las enormes dificultades que suponen que estos casos sean conocidos por las autoridades a menos que un/a adulto/a pregunte al menor, directamente, por su experiencia. Es preciso tener en cuenta que, aunque no todas estas formas de victimización suponen delitos, sí configuran una parte importante de la biografía del menor que es preciso considerar y valorar, especialmente desde el ámbito clínico, dadas las implicaciones que pueden llegar a tener en su desarrollo ${ }^{41}$.

\subsection{Síntesis}

A tenor de todo lo manifestado hasta el momento presente, por lo que respecta a las aportaciones de la "Victimología del desarrollo", la vulnerabilidad subjetiva y situacional de los menores de edad los sitúa en la categoría de grupo especialmente vulnerable que requiere de una mayor protección por parte del Estado.

La vulnerabilidad subjetiva, asociada a características biológicas y psicosociales que generan situaciones de indefensión y de inferioridad, requiere de una mayor intervención respecto de aquellos colectivos de menores de edad que cronológicamente podemos llegar a considerar especialmente vulnerables, que son los ubicados en la período de la infancia, esto es, hasta los 12-13 años; etapa en la que, según la "Victimología del desarrollo", por un lado, presentan una mayor riesgo de victimización por la situación de dependencia del menor, así como por su escaso nivel de desarrollo físico, psicológico y social y, por otro, los supuestos de victimización pueden llegar a generar en los/as menores graves secuelas y trastornos psicopatológicos que podrían incluso acontecer en la etapa adulta, cuando los factores de protección del mismo resultaran insuficientes.

\footnotetext{
40 Morillas Fernández/Patró Hernández/Aguilar Cárceles, Victimología, p. 491.

41 En este sentido, Pereda/ABAd/Guilera, "Victimología del desarrollo", p. 93.
} 
Desde esta perspectiva, si bien se admite como colectivo vulnerable a la totalidad de menores de edad, es decir, sujetos menores de 18 años, el hecho de que los menores de 12-13 años presenten un mayor riesgo no sólo de victimización, sino de desarrollar secuelas psicopatológicas más graves que el resto de menores de edad, es decir, los situados en la franja de edad entre 14 y 17 años, requiere, desde nuestro punto de vista, un abordaje victimológico más tuitivo de estos/as primeros/as, en tanto que grupo de edad más vulnerable en el ámbito victimológico.

En definitiva, las características individuales de los niños y niñas que les sitúan en una posición de especial vulnerabilidad frente al riesgo de ser victimizados/as, así como las posibles secuelas dimanadas de dichos procesos pueden llegar a condicionar su desarrollo evolutivo, justificando, no sólo un mayor abordaje victimológico, sino también un tratamiento jurídico-penal diferenciado en aquellas tipologías delictivas en las que la víctima sea un menor de edad especialmente vulnerable que, al albur de lo manifestado, hace referencia a los menores de 14 años.

Esta clase de victimizaciones traducidas a los tipos delictivos previstos en el ámbito del Código penal español requiere de la existencia de modalidades delictivas, por un lado, tipificadas sobre la base de la minoría de edad del sujeto pasivo, en cuanto que existen determinados bienes jurídicos que sólo deben protegerse respecto del menor de edad (como "child grooming", o el delito de exhibicionismo) ${ }^{42} \mathrm{y}$, por otro, de tipos penales cualificados con marcos punitivos agravados, con motivo de la especial vulnerabilidad del sujeto pasivo, esto es, la minoría de edad del mismo.

Es evidente, por lo tanto, que victimológicamente existen razones que justifican o bien una necesidad de respuesta punitiva, o bien una respuesta punitiva agravada, cuando el sujeto pasivo es un menor de edad, a la vista de los fundamentos victimológicos previstos, pero básicamente sobre la base de la especial vulnerabilidad subjetiva y situacional a las que nos acabamos de referir, debiendo destacarse la necesidad de una intervención especialmente protectora del colectivo de menores de edad que victimológicamente se considera como especialmente vulnerable, habida cuenta, de la edad y de la situación de dependencia en la que se encuentran, esto es, los y las menores hasta 12-13 años.

Sin embargo, no sólo son razones victimológicas las que aconsejan una respuesta punitiva determinante, cuando el sujeto pasivo del delito es una persona menor de edad. Como veremos a continuación, en el siguiente epígrafe, son varios los instrumentos jurídicos internacionales que aconsejan una especial protección de los mismos, cuando se convierten en víctimas de delitos.

42 Muy acertadamente Molina Blázouez, "Los menores y la legislación penal”, p. 464. 


\section{Respuestas jurídico-internacionales: hacia una protección y tutela reforzada de los/as menores de edad víctimas de delitos}

\subsection{Aproximación a los instrumentos internacionales más significativos de tutela de las personas menores víctimas}

Desde el punto de vista jurídico, el reconocimiento del menor como sujeto de derecho y titular de derechos forma parte del fenómeno del reconocimiento y garantía de los derechos humanos, en estrecho vínculo con la evolución del carácter social y democrático del Estado. Como destaca Sanz Hermida, la implantación de los Derechos Humanos fundamentales al ámbito de los/as menores y el reconocimiento de la necesidad de otorgarles una especial protección siguió un proceso paralelo al de los mayores y se ha sustanciado en la elaboración de diversos textos convencionales internacionales ${ }^{43}$, como los que se mencionan a continuación.

La Convención sobre los derechos del niño aprobada por Naciones Unidas el 20 de noviembre de 1989 es un paso adelante en el reconocimiento de los derechos mínimos que se pueden exigir a los Estados en la protección debida a los y las menores de edad. En efecto, los Estados firmantes reconocen los derechos de los/as niños y niñas y, por tanto, se comprometen a adoptar los medios para protegerlos y hacerlos efecti$\operatorname{vos}^{44}$, sobre la base del "interés superior del menor", principio rector que informa la totalidad de la Convención y toda actuación estatal ${ }^{45}$.

En efecto, el tenor literal del artículo 3.1 de la Convención, ahora mencionada, establece lo siguiente: "En todas las medidas concernientes a los niños que tomen las instituciones públicas o privadas de bienestar social, los tribunales, las autoridades administrativas o los órganos legislativos, una consideración primordial a la que se atenderá será el interés superior del menor".

Las disposiciones convencionales previstas en el presente instrumento se aplican a todas las personas que ostentan la condición de niño/a que según el artículo 1 de la Convención comprende "a todo ser humano menor de dieciocho años de edad, salvo que, en virtud de la ley que le sea aplicable, haya alcanzado antes la mayoría de edad”. No existen, en

43 SAnz Hermida, Víctimas de delitos: derechos, protección y asistencia, p. 39.

44 GonzÁlez Agudelo, "El menor como víctima del delito", p. 294.

45 Así se dispone en el tenor literal del artículo 3.1 de la Convención cuando establece lo siguiente: "1. En todas las medidas concernientes a los niños que tomen las instituciones públicas o privadas de bienestar social, los tribunales, las autoridades administrativas o los órganos legislativos, una consideración primordial a que se atenderá será el interés superior del niño". 
este sentido, disposiciones especialmente aplicables a aquel colectivo de menores de edad que, siguiendo lo mencionado en el epígrafe anterior, puedan ser considerados como menores especialmente vulnerables por razón de su vulnerabilidad subjetiva, situacional o su situación de dependencia, que, en el sentido apuntado, se hace extensivo hasta los 12-13 años. El presente instrumento tiene una aplicación global a la totalidad de los y las menores que adquieren dicha condición por ser menores de 18 años.

Sin embargo, si bien es cierto que la Convención de los derechos del niño no parece delimitar franjas de edad en la minoría de edad, por razón de lo que hemos venido considerando como "vulnerabilidad subjetiva o situacional", los Protocolos Facultativos de la Convención de los derechos del niño aprobados en 2002, sí parecen delimitar un colectivo de menores considerados como sujetos especialmente vulnerables. En efecto, así se deduce, por un lado, del Protocolo Facultativo relativo a la venta de niños, la prostitución infantil y la utilización de niños en la pornografía, cuando en su Preámbulo se especifica que "Reconociendo que algunos grupos especialmente vulnerables, en particular las niñas, están expuestos a un peligro mayor de explotación sexual, y que la representación de niñas entre las personas explotadas sexualmente es desproporcionadamente alta" ${ }^{46} \mathrm{y}$, por otro, del Protocolo facultativo de la Convención sobre los Derechos del Niño relativo a la participación de niños en los conflictos armados en cuyo Preámbulo se señala "Tomando nota de la aprobación del Estatuto de Roma de la Corte Penal Internacional, en particular la inclusión entre los crímenes de guerra en conflictos armados, tanto internacionales como no internacionales, del reclutamiento o alistamiento de niños menores de 15 años o su utilización para participar activamente en las hostilidades" 47 .

Así, a tenor del contenido de los Preámbulos de ambos instrumentos, si bien, desde un punto de vista general, del ámbito de la Convención de los derechos del niño, no parece deducirse la existencia de colectivos de menores especialmente vulnerables que precisen de una respuesta tuitiva reforzada, las disposiciones previstas en sendos Preámbulos evidencian el reconocimiento de determinados colectivos de menores que, en función tanto del sexo, como del dato cronológico de la edad, parecen adquirir una situación especialmente vulnerable, frente a la que los Estados tendrán que prestar especial atención, esto es, menores de 15 años y niñas.

46 Protocolo Facultativo Protocolo Facultativo relativo a la venta de niños, la prostitución infantil y la utilización de niños en la pornografía, A/RES/54/263 del 25 de mayo de 2000 .

47 Protocolo facultativo de la Convención sobre los Derechos del Niño relativo a la participación de niños en los conflictos armados, Resolución A/RES/54/263 del 25 de mayo de 2000 . 
En Europa, la protección de los menores debe buscarse en el Convenio Europeo de Derechos Humanos y de las libertades fundamentales, así como en la Carta Social Europea, en lo referente a los derechos económicos y sociales. Aunque sus especificaciones normativas no se refieren directamente a los menores, debe entenderse que cubren a este grupo y así lo ha desarrollado ampliamente la jurisprudencia del Tribunal Europeo de Derechos Humanos y de la Comisión, la que ha interpretado y admitido su aplicación a los niños, forzando modificaciones de legislaciones nacionales y haciendo referencias interpretativas a la Convención de las Naciones Unidas ${ }^{48}$.

En idéntico sentido encontramos el Convenio del Consejo de Europa para la protección de los niños contra la explotación y el abuso sexual, hecho en Lanzarote el 25 de octubre de 2007, que llama la atención de los Estados respecto a la necesidad de implementación de políticas de prevención y de atención a las víctimas, además de la intervención penal, tales como programas y estructuras multidisciplinarias de apoyo a las víctimas (líneas telefónicas y de Internet, asistencia psicológica, etc.) o medidas frente a la victimización secundaria, políticas ${ }^{49}$ que tanto en lo legislativo, como en el conjunto de las actuaciones de las instituciones competentes, han sido en general aplicadas, en opinión de Tamarit Sumalla, con importantes deficiencias ${ }^{50}$. Por lo que respecta al concreto ámbito de aplicación subjetivo, hay que advertir que según el artículo 3 a) del Convenio "por "niño" se entenderá toda persona menor de 18 años", lo que implica que la batería de medidas de tutela y protección de los sujetos que quedan incursos en el concepto de "niño/a" se hace extensiva a todas aquellas personas que se encuentran por debajo de ese límite cronológico de dicha edad, sin que, inicialmente parezcan preverse medidas específicas de protección reforzada por razón de la especial vulnerabilidad en la que se pueda encontrar alguno de estos colectivos.

Ahora bien, contrariamente a esta interpretación, hay que destacar que de las disposiciones del Convenio parece deducirse la existencia de determinados colectivos de menores de edad, frente a los que los Estados Parte tendrán que adoptar las medidas legislativas o de otro tipo que sean necesarias para tipificar como delito las conductas de abuso sexual, especialmente las cometidas "[...] abusando de una situación de especial vulnerabilidad del niño, en particular debido a una discapacidad psíquica o mental o una situación de dependencia” (artículo 18.1 b). A efectos de la aplicación de este apartado, continúa el tenor literal del artículo 18, “[...] cada Parte determinará la edad por debajo de la cual no está permitido realizar actividades sexuales con un niño" (artículo 18.2). En

48 GonzÁlez Agudelo, "El menor como víctima del delito”, p. 295.

49 Así se contempla en el Preámbulo del Convenio.

50 Tamarit Sumalla, "Los delitos sexuales. Abusos sexuales. Delitos contra menores (arts. 178, 180, 181, 183, 183 bis)”, p. 167. 
idéntico sentido, en materia de prostitución de menores (artículo 19), pornografía infantil (artículo 20), corrupción de niños (artículo 22) y proposiciones a niños con fines sexuales (artículo 23), el Convenio se remite al contenido del artículo 18.2, instando a los Estados a adoptar medidas legislativas o de otro tipo necesarias para tipificar como delictivas estas conductas, especialmente cuando el/la menor víctima de las mismas se encuentre por debajo de la edad que el Ordenamiento Jurídico de cada Estado Parte fije como límite para la prohibición absoluta de realización de actividades de naturaleza sexual con los/as mismos/as.

Consecuentemente, los Estados Parte tienen que fijar un límite cronológico de edad, por debajo del que no se permite la realización de actividades de naturaleza sexual con personas menores de edad. Desde esta perspectiva, las conductas objeto de sanción vía Convenio de Lanzarote de 2007, distinguen dos tipos de intervenciones legislativas respecto de la edad de la víctima. Por un lado, la necesidad de intervenir, en general, cuando la víctima de los comportamientos de explotación y abuso sexual se ubique por debajo de los 18 años, y, por otro lado, la necesidad de adoptar medidas legislativas que garanticen la tipificación de dichas conductas, cuando la víctima sea un/a menor que se encuentre por debajo de la edad fijada por cada Estado, en tanto que se trata de comportamientos sexuales no permitidos por el Ordenamiento Jurídico interno. Elemento éste que parece relacionarse directamente con el concepto de vulnerabilidad subjetiva al que nos hemos referido en la primera parte de este trabajo, esto es, de las disposiciones convencionales se deduce la obligación de tipificar o sancionar especialmente las conductas de naturaleza sexual, dirigidas contra determinados colectivos de menores de edad, habida cuenta de su falta de madurez y de desarrollo personal, sin que dicha obligación se haga extensiva a la totalidad de personas que quedan incursas en el concepto de "niño" concretado por el Convenio, esto es, todas aquellas personas menores de 18 años.

Idéntica conclusión se deduce, en última instancia, del tenor literal del artículo 28 c) del Convenio en el que se insta a los Estados a configurar como circunstancia agravante del delito, en la medida en que no sea elemento sustantivo del mismo, "[...] el hecho de que el delito haya sido cometido contra una víctima especialmente vulnerable". El tenor literal de este precepto, evidencia, por lo tanto, que entre el colectivo de menores víctimas hay que distinguir aquellos que se encuentran en una situación especialmente vulnerable; vulnerabilidad que, en el sentido apuntado en el epígrafe anterior, puede estar asociada a cuestiones subjetivas o situacionales, entre otras.

En última instancia, a tenor de las disposiciones del Convenio Europeo de 2007, por lo que respecta a la protección de los menores de edad frente a comportamientos de explotación y abuso sexual, parece deducirse que no todos los menores precisan de igual protección. La necesidad o no de que los Estados Parte configuren una tutela reforzada de este 
colectivo de víctimas estará condicionada, por un lado, a la edad del/de la menor víctima y, por otro, a su situación de vulnerabilidad. En efecto, por lo que respecta a la primera de las condiciones, esto es, la franja de edad en la que los/as menores víctimas se encuentran, la mencionada tutela reforzada, en términos generales, deberá garantizarse a aquellas personas que se encuentren por debajo del límite de edad que el Ordenamiento Jurídico estatal haya fijado para los comportamientos de naturaleza sexual no permitidos con menores de edad, habida cuenta de la falta de madurez y de desarrollo personal en los que se encuentra el/a menor. En segundo lugar, en relación a la vulnerabilidad del/a menor de edad, lejos de hacer referencia la misma al dato cronológico de la edad del menor (que ya queda incurso en la condición anterior), parece referirse a situaciones de vulnerabilidad situacional, en el sentido mencionado en el primer epígrafe de este trabajo.

Por lo que respecta a la tutela específica de los y las menores de edad en cuanto víctimas de delitos a nivel de la Unión Europea, cabe destacar, en primer lugar, la Decisión-Marco 2002/629/JAI, relativa a la trata de seres humanos, de 19 julio 2002, dirigida a la adopción de medidas legislativas contra la trata de seres humanos en la que figuraban definiciones, tipificaciones y sanciones comunes ${ }^{51}$. En su considerando número 5 la presente Decisión-Marco ya se refería directamente a los/as menores de edad, calificándolos/as como colectivo más vulnerable y que presentaban un mayor riesgo de ser víctimas ${ }^{52}$. Si bien, inicialmente, la presente Decisión-Marco acogía un concepto amplio de "niño", referido a toda persona menor de 18 años (artículo 4.1), la misma instaba a los Estados a aumentar los marcos punitivos de los tipos penales de trata, cuando la víctima fuera una "persona especialmente vulnerable", identificada ésta, no con cualquier menor de 18 años, sino, con aquel colectivo de menores que se ubicara por debajo de la edad de mayoría sexual, tal como se desprendía de su artículo 2 b) ${ }^{53}$. Esto es, se venía considerando que los Estados debían fijar una edad de mayoría sexual, no necesariamente coincidente con la mayoría de edad jurídica (18 años), por debajo de la que no sólo no se consentían actos de naturaleza sexual, sino que, en lo referente al delito de trata, supondría un incremento del marco punitivo, al implicar un mayor desvalor de acción, a la vista de que el menor víctima de trata con fines de explotación sexual,

51 En este sentido se recoge en el Considerando 1 de la Decisión-Marco 2002/629/JAI.

52 Así lo recoge el mencionado Considerando 5: "Los niños son más vulnerables y, por tanto, corren un mayor riesgo de ser víctimas".

53 En este sentido, el tenor literal del artículo 2 b), establecía lo siguiente: tal y como se desprendía del tenor literal de su artículo 2 b): “[...] Se considerará que una víctima es particularmente vulnerable, al menos, cuando la víctima esté por debajo de la edad de mayoría sexual según la legislación nacional y la infracción se haya cometido con fines de explotación de la prostitución ajena o a ejercer otras formas de explotación sexual, incluida la pornografía $[\ldots]$ ”. 
no disponía del nivel de madurez suficiente como para tomar decisiones en materia de actividades sexuales.

La presente Decisión-Marco fue sustituida por la Directiva 2011/36 del Parlamento Europeo y del Consejo del 5 de abril, relativa a la prevención y a la lucha contra la trata de seres humanos y a la protección de las víctimas. En su Considerando 8 indica que "Los menores son más vulnerables que los adultos y corren, por tanto, mayor riesgo de ser víctimas de la trata de seres humanos. En la aplicación de la presente Directiva el interés superior del menor debe ser una consideración primordial, de conformidad con la Carta de los Derechos Fundamentales de la Unión Europea y la Convención de las Naciones Unidas de 1989 sobre los Derechos del Niño". En este mismo sentido, se insiste en la necesidad de adoptar medidas especiales de protección hacia los menores víctimas de trata, poniendo especial énfasis en la búsqueda de su recuperación física, psicosocial y en encontrar una solución duradera a su caso ${ }^{54}$, tal y como dispone el tenor literal de los artículos 13, 14 y 15 de la misma.

En segundo lugar, la Decisión-Marco 2004/68/JAI, relativa a la lucha contra la explotación sexual de los niños y la pornografía infantil, de 22 diciembre de 2003, a través de la que se pretendían adoptar medidas

54 Téngase en cuenta, en este sentido, lo dispuesto en el Considerando 22 y en el 23 , cuando recogen lo siguiente: “22. Los Estados miembros deben velar por que, además de las medidas destinadas a todas las víctimas de la trata de seres humanos, se prevean medidas específicas de asistencia, apoyo y protección para las víctimas que son menores. Estas medidas deben concederse en el interés superior del niño de conformidad con la Convención de las Naciones Unidas de 1989 sobre los Derechos del Niño. En caso de que la edad de la víctima sea incierta y haya razones para creer que tiene menos de dieciocho años, debe presumirse que se trata de un menor y debe prestársele inmediatamente asistencia, apoyo y protección. Las medidas de asistencia y apoyo destinadas a las víctimas que son menores deben centrarse en asegurar su recuperación física y psicosocial y en encontrar una solución duradera a su caso. El acceso al sistema educativo contribuiría a que los menores se reintegraran en la sociedad. Como quiera que los/as menores víctimas de la trata son particularmente vulnerables, deben preverse medidas de protección adicionales para protegerlos durante los interrogatorios que se lleven a cabo en las investigaciones y actuaciones judiciales"”.

“23. Debe prestarse una atención especial a los menores no acompañados víctimas de la trata de seres humanos, ya que necesitan asistencia y apoyo específicos por razón de su situación de vulnerabilidad particular. Desde el momento en que se descubra que un menor no acompañado es víctima de la trata de seres humanos, y hasta que se halle una solución permanente, los Estados miembros deben aplicar medidas de acogida adecuadas a las necesidades del menor y garantizar que se apliquen las correspondientes garantías procesales. Deben tomarse las medidas necesarias para que, en su caso, se nombre a un tutor o representante, con objeto de proteger los intereses del menor. Debe adoptarse, en el plazo más breve posible, una decisión sobre el futuro de cada uno de los menores no acompañados víctimas, con objeto de hallar soluciones duraderas basadas en una evaluación individual del interés superior del menor, que debe ser la consideración primordial. Una solución duradera puede ser el retorno y la reintegración al país de origen o al país de retorno, la integración en la sociedad de acogida, la concesión del estatuto de protección internacional o la concesión de otro estatuto con arreglo al Derecho nacional del Estado miembro". 
legislativas contra la explotación sexual de los niños y la pornografía infantil en las que figuraban definiciones, tipificaciones y sanciones comunes ${ }^{55}$. Al igual que sucedía en los instrumentos internacionales hasta ahora mencionados, la presente Decisión-Marco delimitaba su ámbito de aplicación subjetivo sobre la base de los menores de 18 años ${ }^{56}$, en principio, sin establecer diferencia alguna por límites de edad.

A pesar de la previsión, lo cierto es que la Decisión-Marco instaba a los Estados parte a la incorporación en el ámbito de sus códigos Penales de tipos cualificados, cuando los sujetos pasivos de las conductas que pretendían ser objeto de sanción se dirigían contra "un niño que no hubiera alcanzado la edad del consentimiento sexual según el derecho nacional" ${ }^{57}$. Una previsión normativa como la presente, que acogía la cualificación de tipos penales cuando concurriera la mencionada circunstancia, no parecía hacerse extensiva a la totalidad de los/as menores de edad, es decir, a la totalidad de personas menores de 18 años, a pesar de la disposición normativa del artículo 1 de la presente Decisión-Marco. Si el sustento normativo de la cualificación típica residía en el hecho de que la víctima no hubiera alcanzado la edad para el consentimiento sexual, esto es, no dispusiera de madurez suficiente para la toma de decisiones en materia sexual, a sensu contrario, esta disposición sólo era de aplicación en aquellos supuestos en los que el/a menor víctima no hubiera superado un determinado límite de edad, que sería delimitado por el Ordenamiento jurídico de cada Estado. Por encima de dicha franja de edad, y hasta el límite de los 18 años previstos en la Decisión - Marco, la utilización de menores para actividades de explotación sexual y de pornografía infantil sería objeto de tipificación, sin aumento de marcos punitivos, más allá de lo previsto en los tipos básicos de cada ordenamiento jurídico.

Posteriormente, la Directiva 2011/92/UE del Parlamento y del Consejo, de 13 de diciembre de 2011, relativa a la lucha contra los abusos sexuales y la explotación sexual de los menores y la pornografía infantil y por la que se sustituye la Decisión marco 2004/68/JAI del Consejo, aborda desde una perspectiva más integral la protección y tutela de los menores, en cuanto sujetos pasivos de conductas de naturaleza sexual. En idéntico sentido al iniciado por la Decisión-Marco de 2004, la presente directiva se refiere a los/as menores, como a toda persona menor de 18 (artículo 2 a), pero incide, igualmente, en la existencia de una «edad de consentimiento sexual" que, según el artículo 2 c) se identifica con

55 En este sentido se recoge en el Considerando 1 de la Decisión-Marco 2004/68/JAI.

56 Téngase en cuenta el contenido del artículo 1 a) de la Decisión-Marco 2004/68/JAI donde se dispone lo siguiente: "A los efectos de la presente Decisión Marco se entenderá por:

a) "Niño", toda persona menor de 18 años".

57 Así se recoge respecto de la sanción de las conductas de explotación sexual y pornografía infantil en los artículos 5.2.b) y 5.2. c). 
"la edad por debajo de la cual, de conformidad con el Derecho nacional, está prohibido realizar actos de carácter sexual con un menor", lo que nos lleva, necesariamente, a la delimitación de una franja de edad que, ubicada en el marco de lo que viene concibiéndose como minoría de edad sexual, alcanza la capacidad mínima como para ser considerada "edad de consentimiento sexual", por debajo de la misma, prima el interés superior del menor, entendiéndose que los/as menores ubicados por debajo de esta, carecen de capacidad para consentir en sus relaciones de naturaleza sexual.

El límite de la denominada "edad del consentimiento sexual" en el caso de menores que participen en actos de naturaleza sexual, determinará, en algunos supuestos, la sanción de dichas conductas sólo cuando sean cometidas con menores que no hayan alcanzado la "edad del consentimiento sexual" 58 , y en otras ocasiones, la configuración de tipos penales cualificados ${ }^{59}$.

${ }^{58}$ Así se desprende, por ejemplo, del tenor literal de los artículos 3.2, 3.3. y 3.4, en el sentido que a continuación se recoge:

"Artículo 3.2. Hacer, con fines sexuales, que un menor que no ha alcanzado la edad de consentimiento sexual presencie actos de carácter sexual, aunque no participe en ellos, se castigará con penas privativas de libertad de una duración máxima de al menos un año.

Artículo 3.3. Hacer, con fines sexuales, que un menor que no ha alcanzado la edad de consentimiento sexual presencie abusos sexuales, aunque no participe en ellos, se castigará con penas privativas de libertad de una duración máxima de al menos dos años.

Artículo 3.4. Realizar actos de carácter sexual con un menor que no ha alcanzado la edad de consentimiento sexual se castigará con penas privativas de libertad de una duración máxima de al menos 5 años".

59 Téngase en cuenta, por ejemplo, lo dispuesto en algunas modalidades de abuso sexual, esto es, artículos 3.5, 3.6 y 4:

"Artículo 3.5: alizar actos de carácter sexual con un menor

i) abusando de una posición reconocida de confianza, autoridad o influencia sobre el menor, se castigará con penas privativas de libertad de una duración máxima de al menos ocho años si el menor no ha alcanzado la edad de consentimiento sexual, y de al menos tres años si el menor ha alcanzado esa edad, o

ii) abusando de una situación especialmente vulnerable del menor, debida en particular a una discapacidad física o mental o a una situación de dependencia, se castigará con penas privativas de libertad de una duración máxima de al menos ocho años si el menor no ha alcanzado la edad de consentimiento sexual, y de al menos tres años si el menor ha alcanzado esa edad, o

iii) empleando coacción, fuerza o amenazas, se castigará con penas privativas de libertad de una duración máxima de al menos diez años si el menor no ha alcanzado la edad de consentimiento sexual, y de al menos cinco años si el menor ha alcanzado esa edad.

Artículo 3.6: Emplear coacción, fuerza o amenazas con un menor para que participe en actos de carácter sexual con un tercero se castigará con penas privativas de libertad de una duración máxima de al menos diez años si el menor no ha alcanzado la edad de consentimiento sexual, y de al menos cinco años si el menor ha alcanzado esa edad.

Artículo 4: Los Estados miembros adoptarán las medidas necesarias para garantizar la punibilidad de las conductas dolosas mencionadas en los apartados 2 a 7 .

2. Hacer que un menor participe en espectáculos pornográficos, captarlo para que lo haga, lucrarse por medio de tales espectáculos, o explotar de algún otro modo a un menor para esos fines, se castigará con penas privativas de libertad de una duración máxima de 
Desde este mismo prisma, conviene referirse a la previsión normativa del artículo 8 de la Directiva en la que manera expresa se prevé la posibilidad de que los Estados Parte, dejen impunes determinados actos de carácter sexual, cuándo estos tienen lugar con menores próximos por edad al grado de desarrollo o madurez física y psicológica, siempre que los actos no impliquen abusos, en el sentido recogido por el mencionado precepto: "Actos de carácter sexual consentidos

1. Quedará a la discreción de los Estados miembros decidir si el artículo 3, apartados 2 y 4, será aplicable a los actos de carácter sexual consentidos entre personas próximas por edad y grado de desarrollo o madurez física y psicológica, siempre que los actos no impliquen abusos.

2. Quedará a la discreción de los Estados miembros decidir si artículo 4, apartado 4, será aplicable a un espectáculo pornográfico que tenga lugar en el contexto de una relación consentida cuando el menor haya alcanzado la edad de consentimiento sexual, o entre personas próximas por edad y grado de desarrollo o madurez física y psicológica, siempre que los actos no impliquen abusos ni explotación y que no medie dinero u otras formas de remuneración o contraprestación a cambio del espectáculo pornográfico.

3. Quedará a la discreción de los Estados miembros decidir si el artículo 5, apartados 2 y 6, será aplicable a la producción, adquisición o posesión de material pornográfico en el que intervengan menores que hayan alcanzado la edad de consentimiento sexual, cuando ese material haya sido producido y se posea

al menos cinco años si el menor no ha alcanzado la edad de consentimiento sexual, y de al menos dos años si el menor ha alcanzado esa edad.

3. Emplear coacción, fuerza o amenazas con un menor para que participe en espectáculos pornográficos, se castigará con penas privativas de libertad de una duración máxima de al menos ocho años si el menor no ha alcanzado la edad de consentimiento sexual, y de al menos cinco años si el menor ha alcanzado esa edad.

4. Asistir a sabiendas a espectáculos pornográficos en los que participen menores se castigará con penas privativas de libertad de una duración máxima de al menos dos años si el menor no ha alcanzado la edad de consentimiento sexual, y de al menos un año si el menor ha alcanzado esa edad.

5. Hacer que un menor se prostituya, captarlo para que lo haga, lucrarse con ello, o explotar de algún otro modo a un menor para esos fines se castigará con penas privativas de libertad de una duración máxima de al menos ocho años si el menor no ha alcanzado la edad de consentimiento sexual, y de al menos cinco años si el menor ha alcanzado esa edad.

6. Emplear coacción, fuerza o amenazas con un menor para que se prostituya, se castigará con penas privativas de libertad de una duración máxima de al menos diez años si el menor no ha alcanzado la edad de consentimiento sexual, y de al menos cinco años si el menor ha alcanzado esa edad.

7. Realizar actos de carácter sexual con un menor, recurriendo a la prostitución infantil, se castigará con penas privativas de libertad de una duración máxima de al menos cinco años si el menor no ha alcanzado la edad de consentimiento sexual, y de al menos dos años si el menor ha alcanzado esa edad". 
con el consentimiento de estos y se emplee exclusivamente para el uso privado de las personas involucradas, siempre que los actos no hayan implicado abusos".

A la vista de todo lo mencionado respecto a la normativa reguladora de actos de naturaleza sexual con personas menores de edad, en el sentido mencionado respecto de otros instrumentos ya aludidos, cabe concluir que la "edad de consentimiento sexual" mencionada no ha de ser necesariamente coincidente con la mayoría de edad jurídica, fijada, con carácter general, en los 18 años. Los Estados dispondrán de discrecionalidad para determinar a partir de qué límite de edad cronológico se puede entender que el menor de edad alcanza un grado de desarrollo y de madurez física y psicológica para consentir en sus relaciones sexuales. Alcanzado dicho límite de "edad de consentimiento sexual", la conducta de naturaleza sexual llevada a cabo con dicho colectivo de menores, será, en algunas ocasiones, sólo incriminada como tipo básico, y en otras, devendrá en situaciones de impunidad, a la vista de la capacidad de consentimiento sexual que se les presupone a dichos/as menores.

El último de los instrumentos a tener en cuenta, desde la perspectiva de proceder a una tutela especial de los menores de edad, reside en las previsiones normativas de la Directiva 2012/29/UE sobre derechos de las víctimas de delitos, en la que se refiere de forma más exhaustiva al reconocimiento de derechos, protección, tutela y asistencia de los/as menores de edad en situaciones de victimización. En efecto, la Directiva, en el mismo sentido expresado por la Convención de los Derechos del niño de 1989, y por el resto de instrumentos hasta ahora mencionados, parte como principio rector del "Interés superior del menor", reconociendo a todos/as los menores víctimas de delitos la facultad de ejercitar plenamente los derechos que les son reconocidos en cuanto tal, de forma que tenga en cuenta su capacidad de juicio propio ${ }^{60}$. Sobre la base del reconocimiento del interés superior del menor, la Directiva destaca especialmente la situación de aquellos menores que por su edad, su grado de madurez, su opinión, sus necesidades o inquietudes requieran de planteamientos especialmente sensibles ${ }^{61}$. Así, sin recurrir al criterio cronológico (puesto que desde un punto de vista general identifica a los/as menores con las personas menores de 18 años ${ }^{62}$ de la edad, la Directiva reconoce

\footnotetext{
60 Así se deduce de los Considerandos números 14, 19 y 42 de la Directiva 2012/29/UE.

61 En este sentido se pronuncia el artículo 2.1 de la Directiva, cuando dispone: "Cuando la víctima sea un menor de edad, los Estados miembros velarán porque en la aplicación de la presente Directiva prime el interés superior del menor y dicho interés sea objeto de una evaluación individual. Prevalecerá un planteamiento sensible a la condición de menor, que tenga en cuenta la edad del menor, su grado de madurez y su opinión, al igual que sus necesidades e inquietudes. El menor y su representante legal, si lo hubiere, serán informados de toda medida o derecho centrado específicamente en el menor".

62 Véase, el artículo 2.1.c).
} 
la existencia de menores de edad que requieren de un tratamiento especialmente "sensible" por mor de su edad o de su madurez o falta de la misma. En este sentido, sin especificar si se pueden distinguir franjas de edad en las que el grado de madurez de los/as menores requieran de respuestas especiales, se recoge una disposición genérica para que los Estados tengan en cuenta estas circunstancias biológicas y psicológicas desde la perspectiva del desarrollo de una política victimal integral que acoja las especificidades de los colectivos más sensibles o vulnerables.

\subsection{Especial protección de los menores de edad víctimas de delitos desde el punto de vista internacional. Hacia una tutela reforzada del/a menor víctima, sustentada en su grado de madurez y desarrollo}

A la vista de todo lo manifestado, la totalidad de los instrumentos ahora mencionados configuran la minoría de edad penal como una categoría "victimológica" que, sobre la base del principio del "interés superior del menor", requiere de respuestas victimales y sustantivas diferentes a las víctimas mayores de edad.

Sin entrar en concretas políticas víctimales que deben pivotar sobre la base de la protección integral de los/as menores víctimas, por lo que respecta a las obligaciones internacionales derivadas de los instrumentos ahora mencionados, la intervención jurídico penal frente a supuestos de victimización de menores de edad, se condiciona, en algunas ocasiones, a la situación de especial vulnerabilidad en la que se encuentran algunos de estos menores y, en otras, a la denominada "edad de consentimiento sexual" (para los supuestos de comportamientos de naturaleza sexual).

Por lo que respecta al primero de los condicionantes, esto es, la existencia de colectivos de menores de edad especialmente vulnerables, víctimas de delitos, desde un punto de vista general, no son pocos los instrumentos normativos internacionales que han puesto el acento en la existencia de supuestos que generan una situación de indefensión en el menor de edad víctima de delitos que nos recuerda a los supuestos de vulnerabilidad situacional, ya aludida en el primer epígrafe de este trabajo. En efecto, son varios los instrumentos normativos internaciones que hacen referencia a la necesidad de incrementar los marcos punitivos de los tipos delictivos en los que las víctimas son menores de edad especialmente vulnerables, por razón del sexo (en el caso de niñas), de la situación de dependencia o, de su falta de madurez y de desarrollo físico y/o psicológico de los mismos. En estos supuestos, el incremento de la respuesta punitiva pivota sobre la base del mayor desvalor de acción que en estas modalidades delictivas genera la situación de indefensión de la víctima sobre el sujeto activo. 
En segundo lugar, en relación, fundamentalmente, a las obligaciones internacionales orientadas a la incriminación de las conductas de naturaleza sexual, la intervención del "Ius Puniendi" de cada uno de los Estados Parte, está condicionada por la denominada "edad del consentimiento sexual" del/a menor víctima. En efecto, en el sentido ya manifestado los instrumentos internacionales que se ocupan de la incriminación de las conductas de naturaleza sexual en las que se involucra a menores de edad, contemplan respuestas punitivas diferentes, a tenor de que el/la menor víctima haya o no alcanzado la denominada "edad del consentimiento sexual”, fijada por cada Estado Parte. A mayor abundamiento, los instrumentos internacionales ahora mencionados, dejan discrecionalidad a los Estados para proceder a la delimitación de lo que viene concibiéndose como "edad del consentimiento sexual", entendida esta como el límite cronológico de edad a partir de la que cada Estado Parte presupone la concurrencia en el menor de edad, de un grado de madurez y de desarrollo que le permite adoptar decisiones de naturaleza sexual. Este límite cronológico de edad, desde el punto de vista del Ordenamiento Jurídico interno de cada Estado, fija la delimitación entre las conductas sexuales consentidas y aquellas que requerirán de una intervención penal.

Por lo que respecta a las conductas objeto de sanción penal, derivadas de las disposiciones normativas presentes en los instrumentos ahora mencionados, se distinguen dos tipos de intervenciones: en primer lugar, la sanción genérica de aquellas conductas de naturaleza sexual con menores de 18 años, y, en segundo lugar, la necesidad de adoptar medidas legislativas que garanticen la tipificación de dichas conductas cuando la víctima sea un/a menor que se encuentre por debajo de la "edad de consentimiento sexual", fijada por cada Estado.

En ambos casos, nos referimos a comportamiento que requieren de la intervención del ius puniendi del Estado en el primero de los supuestos, motivados por la existencia de menores de 18 años en los que concurren otra serie de circunstancias que les aboca a una situación de vulnerabilidad de la que abusa el sujeto activo y, en el segundo de los supuestos, como consecuencia del especial desvalor de acción que se desprende en estas conductas, habida cuenta de la vulnerabilidad subjetiva del menor de edad, de la que igualmente abusa el sujeto activo, vinculada directamente a la incapacidad para la adopción de decisiones de naturaleza sexual, debido a la falta de madurez y de desarrollo físico y psicológico del menor víctima.

En definitiva, respecto a la necesidad de tutela penal de los menores de edad víctimas, de las disposiciones normativas orientadas a la protección de los mismos caben deducir dos conclusiones. En primer lugar, que, con carácter general, se desprende una cierta necesidad de intervención penal respecto de los menores de 18 años, en cuanto víctimas de delitos, que sobre la base del principio de "interés superior del menor", justifica una respuesta punitiva específica. 
Y, en segundo lugar, el conjunto de disposiciones internacionales ahora mencionadas insta a los Estados Parte a adoptar medidas legislativas que garanticen, específicamente, o bien la tipificación, o bien la configuración de tipos penales cualificados, frente a comportamientos ilícitos en los que se involucre a menores que no hayan alcanzado un determinado límite cronológico de edad, debiendo ser fijado el mismo por cada uno de los Estados Parte. La necesidad de una intervención penal reforzada sobre la base del denominado "límite cronológico de edad", se sustenta en atención a la falta de madurez y de desarrollo físico y psicológico de los menores; circunstancia ésta que les ubica en una situación de indefensión de la que se prevale el sujeto activo, comportando un mayor desvalor de acción y, precisando, por lo tanto, una respuesta punitiva cualificada.

A pesar de la discrecionalidad que disponen los Estados para la fijación del denominado "límite cronológico de edad", que justificará una tutela penal reforzada de determinados menores víctimas, el mencionado límite tendrá que concretarse sobre la base del grado de madurez y de desarrollo físico y psicológico de los menores que implica el reconocimiento del mismo como sujeto y titular de derechos, en el ámbito del Ordenamiento Jurídico de cada Estado Parte. Por debajo de dicho límite, la intervención jurídico-penal para la tutela de los mismos, en cuanto víctimas de delitos, requerirá de una respuesta reforzada, a la vista de la situación de vulnerabilidad en la que los mismos se encuentran.

\section{Especial protección del menor de edad en el ámbito del ordenamiento jurídico español}

En el Ordenamiento jurídico español hay un reconocimiento expreso de los derechos de los menores. La Constitución establece en el artículo 39.4 que "los niños gozarán de la protección prevista en los acuerdos internacionales que velan por sus derechos", por lo tanto, al margen de las cuestiones específicas de protección jurídica de los mismos desarrolladas en el ámbito civil y procesal, por lo que respecta a la respuesta derivada del "Ius Puniendi" del Estado, la minoría de edad penal del sujeto pasivo ha incidido punitivamente desde una doble perspectiva, por un lado, sobre la base del aumento de los marcos punitivos de los tipos penales en los que la víctima es menor de edad y, por otro, sobre la base de la existencia de determinadas medidas orientadas a la tutela de los mismos, como la pena del artículo $57 \mathrm{CP}$, la inhabilitación especial para el ejercicio de la patria potestad o la del artículo 192 del Código penal.

Comenzando por la segunda de las cuestiones, y sin pretender abordar un análisis exhaustivo de la totalidad de las penas orientadas directamente a la protección del/de la menor víctima del delito, nos limitaremos a referirnos a las respuestas jurídico-penales que se orientan directamente a la protección de la persona menor de edad, cuando las 
personas encargadas de tutelarlos los convierten en víctimas de delitos. En estos supuestos, como destaca Molina Blázquez, se hace evidente que debe protegerse al menor de quien ha ejercido tan deficientemente su deber de velar por él ${ }^{63}$.

\subsection{Penas de inhabilitación para el ejercicio de la patria potestad, guarda y custodia de los menores}

Con el Código penal ${ }^{64}$ de 1995 se introdujo la pena de inhabilitación especial para el ejercicio de la patria potestad, tutela, curatela, guarda y acogimiento en el artículo 39 b) CP. Esta pena, según el artículo 46 CP, priva al penado de los derechos inherentes a la primera, y supone una extinción de las demás, así como la incapacidad para obtener nombramiento para dichos cargos durante el tiempo de la condena. La privación de patria potestad encuentra su fundamento en el ejercicio inadecuado o negligente de los deberes inherentes a la misma por parte de su titular, manifestado en la comisión de un delito, y tiene como finalidad la protección de uno o varios de sus hijos, en cuyo interés se impone ${ }^{65}$.

La pena de inhabilitación especial para la patria potestad se introdujo con carácter principal en los delitos pensados para proteger específicamente bienes jurídicos del menor, y con carácter accesorio, como el resto de las inhabilitaciones especiales contenidas en el CP, cuando se impusiera una pena de prisión inferior a 10 años, por la comisión de algún otro delito y éste hubiera tenido relación con alguna de estas instituciones.

La reforma operada en el año 2010 introdujo una modificación de calado, al incorporar una nueva pena, la privación de patria potestad y la posibilidad de que tanto la inhabilitación especial para el ejercicio de la patria potestad, como la propia privación de la patria potestad sean impuestas como penas accesorias, siempre que se sancione un delito con pena de prisión, ya sea superior o inferior a 10 años. Se conforma, eso sí, como una auténtica pena que habrá de quedar sometida a los principios y reglas que rigen esta clase de sanciones; especialmente al principio de legalidad, en cuya virtud su aplicación ha de quedar reservada a aquellos delitos en los que se prevé expresamente o a los supuestos en los que el propio Código Penal autorice su aplicación como accesoria de la prisión por existir una relación directa entre el ejercicio de la patria potestad y el delito cometido por su titular ${ }^{66}$.

\footnotetext{
63 Molina BlázQuez, "Los menores y la legislación penal”, p. 465.

64 En adelante, CP.

65 Gutierrez Castañeda, "Penas privativas de derechos", p. 102.

66 Gutierrez Castañeda, "Penas privativas de derechos", p. 102.
} 
En ambos casos, nos encontramos ante penas que se orientan a proteger al menor cuando han sido las personas encargadas de velar por él quienes la han convertido en víctima del delito ${ }^{67}$. La diferencia entre ambas reside en el hecho de que la inhabilitación para el ejercicio de la patria potestad no comporta la pérdida de la titularidad de la misma, sino que limita su ejercicio temporalmente; mientras que la privación de la patria potestad supone la extinción de la misma respecto del progenitor al que afecte la resolución judicial. En ambas penas, sin embargo, subsisten los derechos que el ordenamiento jurídico concede al menor respecto de sus progenitores y el progenitor queda obligado por los derechos correlativos ${ }^{68}$.

\subsection{Penas que suponen alejamiento de menores}

La reforma del 2015 introdujo en el artículo 192.3 inciso segundo, una pena de inhabilitación especial para cualquier profesión u oficio, sea retribuido o no, que conlleve contacto regular y directo con menores de edad.

La pena se impondrá a los responsables de los delitos de los Capítulos II bis (abuso y agresiones sexuales a menores de 16 años) o V (prostitución y explotación sexual y corrupción de menores) y tendrá una duración superior entre tres y cinco años al de la duración de la pena de privación de libertad impuesta en su caso en la sentencia, o por un tiempo de dos a diez años cuando no se hubiera impuesto una pena de prisión, atendiendo proporcionalmente a la gravedad del delito, el número de los delitos cometidos y a las circunstancias que concurran en el condenado.

Como muy acertadamente destaca Molina Blázquez, la pena adolece de un defecto, esto es, que se aplica tan solo a ciertos delitos sexuales, cuando podría ser conveniente aplicarla en todos los casos, como los delitos de maltrato en el ámbito educativo cometidos por el personal encargado de los menores.

\subsection{Incidencia de la minoría de edad en la parte especial del Código}

\subsubsection{Introducción}

Sobre la base de lo mencionado hasta ahora y trayendo a colación las conclusiones vertidas en el epígrafe correspondiente a aspectos

67 Bach Fabregó/Gimeno Cubero, “Clases y contenido de penas y ejecución de las penas", p. 83.

68 Molina BlázQuez, "Los menores y la legislación penal”, p. 466. 
victimológicos y las específicas de las obligaciones jurídicas estatales, derivadas de los instrumentos internacionales orientados la tutela del menor víctima mencionados anteriormente, corresponde en este momento analizar los fundamentos jurídicos, de política criminal o basados en evidencias psicológicas que permiten al legislador penal, la configuración de tipos penales reforzados o cualificados, cuando de un menor víctima se trata.

Por lo tanto, sobre la base de la necesidad de establecer una "edad mínima del consentimiento", por debajo de la cual las conductas ilícitas contra menores de edad requieren de una intervención penal reforzada, sobre la base de tipos penales cualificados o específicos, corresponde a continuación analizar los criterios adoptados por el legislador penal español para fijar dicha "edad mínima del consentimiento", actualmente ubicada, en algunos delitos en los 12 años (delitos contra la integridad física, artículo 148.3CP) y, en otros, en los 16 años. Desde un punto de vista general, no deja de sorprender, por un lado, la inexistencia de criterio unívoco a la hora de delimitar dónde hay que fijar el límite cronológico de edad, por debajo del cual, es precisa una intervención penal reforzada (en unas ocasiones a los 12 y en otras a los 16) y, por otro, cuáles son los fundamentos que permiten sustentar la necesidad de una diferente respuesta penal, si como parece deducirse, tanto de las aportaciones victimológicas, como de las disposiciones internacionales mencionadas, tienen una vinculación con la ausencia de grado de madurez y de desarrollo físico y psicológico de los concretos menores víctimas.

Con la finalidad de concretar los fundamentos sobre los que sustenta la adopción de los dos límites cronológicos de edad ahora mencionados, esto es, 12 y 16 años, vamos a proceder a realizar una aproximación a cada uno de los tipos delictivos que recogen los mencionados límites de edad. Así, centraremos la atención en las razones que se configuran como el sustento de la fijación de los mismos en los siguientes preceptos: artículo 140.1.1 CP (16 años); artículo 148.3 CP (12 años); artículos 183, 183 bis, 183ter y 183 quater CP (16 años); y, por último, artículo 189.2 (16 años).

4.3.2. Aproximación a los tipos delictivos de tutela penal reforzada cuando el sujeto pasivo es una víctima menor de edad

\subsubsection{Especial protección de los/as menores de edad en los delitos contra la vida y contra la integridad física}

Comenzando por el primero, esto es, el artículo $140.1 \mathrm{CP}$ recoge el siguiente tenor literal: “1. El asesinato será castigado con la pena de prisión permanente revisable cuando concurra alguna de las siguientes circunstancias: 1. Que la víctima sea menor de 16 años de edad [...]". 
Una aproximación a la Exposición de Motivos de la Ley Orgánica de reforma del 2015, lejos de concretar el fundamento sobre el que se sustenta la incorporación de esta primera forma cualificada del delito de asesinato, fundamentada en el dato cronológico de la edad de la víctima (esto es, menor de 16 años), se limita simplemente a mencionar la incorporación de esta modificación en el ámbito del Código Penal, sin aportar justificación, ni razón de política-criminal alguna ${ }^{69}$. Frente a la presente ausencia de razonamiento jurídico alguno y, a la vista de la gran confusión existente en el ámbito interno del Ordenamiento Jurídico español alrededor de los límites de edad (téngase en cuenta que la mayoría de edad civil se concreta a los 18 años; la emancipación es posible a partir de los 16; la edad penal comienza a los 14; la escolarización es obligatoria hasta los 16 años; la edad mínima para trabajar es de 16 años, pero se puede otorgar testamento desde los 14 años; se puede contraer matrimonio a los 16 años; la edad mínima del consentimiento sexual es de 16 años, etc.), la fijación, en el ámbito del precepto ahora mencionado del límite de 16 años, como circunstancia que cualifica el delito de asesinato y de homicidio es, en opinión de una parte de la doctrina, una decisión completamente arbitraria, puesto que no parece encontrarse ningún criterio político-criminal reconocible, de racionalidad interna y carece de todo sentido valorativo ${ }^{70}$. En efecto, la nueva regulación lleva a la paradoja de considerar como asesinato las conductas lesivas del bien jurídico vida, dirigidas contra los denominados por el Tribunal Supremo "seres constitucionales indefensos", con una pena privativa de libertad de 15 a 25 años, debiendo adquirir la calificación jurídica de homicidio, cuando dichas conductas se dirijan contra una persona de, por ejemplo, 15 años, siendo sancionadas con una pena de 15 a 22 años y 6 meses por aplicación del artículo 138, en relación con la circunstancia primera

69 Téngase, en cuenta, en este sentido, el punto X de la Exposición de motivos de la Ley Orgánica 1/2015, cuando indica lo siguiente: La reforma prevé la imposición de una pena de prisión permanente revisable para los asesinatos especialmente graves, que son ahora definidos en el artículo 140 del Código Penal: asesinato de menores de dieciséis años o de personas especialmente vulnerables; asesinatos subsiguientes a un delito contra la libertad sexual; asesinatos cometidos en el seno de una organización criminal; y asesinatos reiterados o cometidos en serie. Se revisa la definición de asesinato (no agravado), que pasa a incluir los supuestos en los que se causa la muerte de otro para facilitar la comisión de otro delito o evitar su descubrimiento. Y se amplía el marco penal dentro del cual los tribunales deben fijar la pena justa, si bien se mantiene la imposición de la misma en su mitad superior en los casos de concurrencia de varias de las circunstancias que cualifican el asesinato. Estas mismas circunstancias, por coherencia, pasan a ser también circunstancias que cualifican el delito de homicidio. Al tiempo, se ha previsto también la agravación del homicidio de autoridades, funcionarios y agentes de la autoridad -cuando son víctimas de este delito en el ejercicio de sus funciones o con ocasión de ellas- con la finalidad, especialmente, de reforzar la protección de los agentes de las Fuerzas y Cuerpos de seguridad.

70 En contra Goyena Huerta, “Artículo 140”, p. 62, plantea que la incorporación del límite de la edad en los 16 años en el presente precepto, le dota de una mayor seguridad jurídica que "las siempre inseguras categorías de vulneración por razón de edad". 
del artículo 140.1 CP, algo que, como Álvarez García y Ventura Pünchel destacan, desde el prisma de la diferente gravedad del injusto, no parece respetar los criterios de proporcionalidad ${ }^{71}$.

El tenor del artículo 148.3 CP dispone lo siguiente: "Las lesiones previstas en el apartado 1 del artículo anterior podrán ser castigadas con la pena de prisión de 2 a 5 años, atendiendo al resultado causado o riesgo producido: 3. Si la víctima fuere menor de 12 año o incapaz".

De la redacción del precepto se deduce una presunción de debilidad cuando la víctima fuera menor de 12 años, sobre la base de incapacidad defensiva de la misma, de la que se prevale el sujeto activo ${ }^{72}$ que justifica la cualificación del precepto. La fijación, en el ámbito de las lesiones, de la presente presunción iuris et de iure de incapacidad defensiva por debajo de los 12 años trae causa en la tradición jurídica de entender que los y las menores de 13 años carecían igualmente de capacidad jurídica suficiente como para, no sólo desarrollar algún tipo de resistencia, sino para consentir su sometimiento a determinados comportamientos. Así lo ha venido destacando el Tribunal Supremo cuando indicaba la vulnerabilidad de la víctima esencialmente en relación a la edad "pudiendo ser ésta muy escasa o elevada...siendo lo importante que tal edad incida en la eventual vulnerabilidad de su personalidad" o bien a causa de "la enfermedad que padezca, cualquiera que sea su edad", o incluso en atención a las condiciones objetivas de la comisión delictiva "por la situación en que se encuentre, que debe ser interpretado como algo externo a su personalidad" 73 .

Así, la especial vulnerabilidad predicable en estos supuestos por razón de edad (menores de 12 años) permite extender la tutela penal reforzada de este precepto a personas que presenten una limitación de sus condiciones físicas o psíquicas que merme su capacidad defensiva.

\subsubsection{La "edad del consentimiento sexual del/la menor de edad" en los delitos de naturaleza sexual: ¡Hacia un Derecho Penal moralizante?}

El tercero de los ámbitos y último en el que se observa una tutela penal reforzada es el de la protección de los menores de 16 años en el marco de los delitos de abusos y agresiones sexuales, por un lado y de los supuestos de prostitución y pornografía infantil, por otro, que, responden a la exigencia derivada de las obligaciones internacionales de fijar la edad del consentimiento sexual, situándose, la misma, desde la reforma del 2015, en los 16 años. p. 323.

71 Álvarez García/Ventura Püchel, "Delitos contra la vida humana independiente",

72 Así lo recoge la Fiscalía General Del Estado, Circular 4/2005, p. 22.

73 Así lo recoge el Tribunal Supremo en su sentencia 224/2003, de 11 de febrero. 
Según la exposición de Motivos de la mencionada Ley Orgánica $1 / 2015$ "[...] se introducen modificaciones en los delitos contra la libertad sexual para llevar a cabo la transposición de la Directiva 2011/93/ UE, relativa a la lucha contra los abusos sexuales y la explotación sexual de los menores y la pornografía infantil y por la que se sustituye la Decisión Marco 2004/68/JAI del Consejo. Como novedad más importante, continúa la Exposición de Motivos, se eleva la edad del consentimiento sexual a los dieciséis años. La Directiva define la «edad de consentimiento sexual» como la «edad por debajo de la cual, de conformidad con el Derecho Nacional, está prohibido realizar actos de carácter sexual con un menor.» En la actualidad, la edad prevista en el Código Penal era de trece años, y resultaba muy inferior a la de los restantes países europeos -donde la edad mínima se sitúa en torno a los quince o dieciséis años- y una de las más bajas del mundo. Por ello, el Comité de la Organización de las Naciones Unidas sobre Derechos del Niño sugirió una reforma del Código penal español para elevar la edad del consentimiento sexual, adecuándose a las disposiciones de la Convención sobre los Derechos de la Infancia, y así mejorar la protección que España ofrece a los menores, sobre todo en la lucha contra la prostitución infantil”.

De esta manera, finaliza la Exposición de Motivos, "la realización de actos de carácter sexual con menores de dieciséis años será considerada, en todo caso, como un hecho delictivo, salvo que se trate de relaciones consentidas con una persona próxima al menor por edad y grado de desarrollo o madurez. Y se establecen agravaciones si, además, concurre violencia o intimidación, o si los abusos consisten en acceso carnal por vía vaginal, anal o bucal, o introducción de miembros corporales u objetos por alguna de las dos primeras vías. En el caso de los menores de edad -de menos de dieciocho años- pero mayores de dieciséis años, constituirá abuso sexual la realización de actos sexuales interviniendo engaño o abusando de una posición reconocida de confianza, autoridad o influencia sobre la víctima [...]"74.

Sobre el contenido de la presente Exposición de motivos, cabe realizar algunas consideraciones.

En primer lugar, que la elevación de la edad del consentimiento sexual hasta los 16 años, presenta un primera problemática asociada a la sanción de conductas en el ámbito de la Ley Orgánica Reguladora de la Responsabilidad penal del menor (LO 5/2000), dado que la presente normativa remite la descripción típica de los hechos delictivos cometidos por menores entre 14 y 18 años, a las disposiciones del Código Penal, lo que implica la posibilidad de sancionar vía LO 5/2000 las relaciones sexuales con menores de 16 años ${ }^{75}$.

\footnotetext{
74 Así se recoge en el punto XII de la Exposición de motivos de la Ley Orgánica 1/2015.

75 TAMARit Sumalla, "Delitos contra la indemnidad sexual de menores", p. 424.
} 
Siguiendo con las disposiciones de la Ley Orgánica 5/2000, la fijación de la edad penal en los 14 años, parece tropezar con la ahora denominada "edad del consentimiento sexual" que el legislador español sitúa a partir de los 16 años. En efecto, la edad mínima para la exigencia de responsabilidad penal se sitúa en los 14 años ${ }^{76}$. A partir de dicha edad se viene interpretando que el menor tiene capacidad de discernimiento y de comprensión que hace posible la exigencia de una responsabilidad derivada del hecho de haber cometido una infracción criminal ${ }^{77}$. En este sentido, se presume que a partir de los 14 años cualquier persona ha adquirido ya la capacidad de comprender lo ilícito, sino de todos, sí de la mayor parte de los comportamientos delictivos ${ }^{78}$, siendo plenamente responsable de sus actos. Consecuentemente la fijación del límite mínimo en los 14 años, implica la inimputabilidad de los menores de dicha edad.

En efecto, existe la convicción de que el menor de 14 años presenta un desarrollo físico y psíquico sumamente incompleto ${ }^{79}$ que fundamenta la inimputabilidad de los mismos ${ }^{80}$ en cuanto no tienen capacidad de culpabilidad. Consecuentemente, los supuestos en los que un menor de 14 años cometa un ilícito penal serán sometidos a la normativa sobre protección de menores.

Pues bien, esta misma argumentación jurídica debería servir para delimitar la edad del consentimiento sexual. En efecto, si a partir de los 14 años, desde el punto de vista de los menores infractores, existe una presunción de haber alcanzado el grado de desarrollo y de madurez necesarios como para comprender el carácter ilícito de sus comportamientos, y por tanto, obrar conforme a dicho conocimiento, consecuentemente dispondrán de idéntica capacidad y de grado de desarrollo y de madurez como para comprender el alcance de su implicación en conductas de naturaleza sexual, debiendo, en estos supuestos, fijarse la "edad del consentimiento sexual" en dicho límite cronológico, o en el que se contemplaba con anterioridad a la reforma del 2015, esto es, en los 13 años. A sensu contrario, fijar la edad del consentimiento sexual

76 Téngase en cuenta el contenido del artículo 40.3 de la Convención de los derechos del niño cuando dispone que los Estados Parte tomarás las medidas apropiadas para promover el establecimiento de leyes y procedimientos en los que examinarán la posibilidad de establecer una edad mínima antes de la cual se supondrá que los niños no tienen capacidad para infringir las leyes penales.

77 MARTín LÓPEZ, "Delincuencia juvenil y normativa internacional”, p. 335; ORNOSA FERnÁndez, Derecho penal de menores, p. 141; SÁnchez García De PAz, "La nueva ley reguladora de la responsabilidad penal del menor”, p. 708; VÁzQUEz GonZÁLEZ, Delincuencia juvenil, p. 218.

78 Véase, por todos, Boldoma Pasamar, “Principales aspectos sustantivos”, p. 1557.

79 Por todos, Higuera Guimerá, Derecho Penal juvenil, p. 308.

80 Tal y como destaca VÁzouez GonzÁLEz, Delincuencia juvenil, p. 207, los niños no tienen capacidad de culpabilidad, esto es, se consideran inimputables ya que su personalidad no ha alcanzado todavía el grado de desarrollo o madurez necesario que les permita comprender el carácter ilícito de su conducta y, por tanto, obrar conforme a este conocimiento. 
en los 16 años (presumiendo que por debajo de dicho límite carecen de madurez y de desarrollo como para adoptar decisiones en dicho ámbito), tal y como se contempla en el ámbito de los delitos de abusos y agresiones sexuales, genera una "dicotomía jurídica" de difícil comprensión. Así, una persona de 16 años podrá ser sancionada penalmente por la comisión de un delito de agresión o abuso sexual (en tanto que se entiende que dispone de un grado de madurez y de desarrollo intelectual que le permite comprender la ilicitud de dicho comportamiento); pero, a sensu contrario, en cuanto sujeto pasivo de cualquiera de dichas conductas, precisa de una tutela penal reforzada, al presumirse que, desde su posición de víctima, no dispone de un grado de madurez y de desarrollo intelectivo que le permita adoptar decisión alguna en dicho ámbito.

A la vista de lo manifestado, la coherencia jurídica requiere de un retorno a la anterior edad del consentimiento sexual, esto es, a los 13 años.

En segundo lugar, la elevación de la edad del consentimiento sexual, genera un sistema de protección único para menores con edades muy diversas, al tiempo que establece otro sistema de protección para una franja muy estrecha (16-17 años). Esta cuestión, obliga a introducir, en todo caso, una cláusula de exclusión de los supuestos en los que, mediando consentimiento por parte del menor, no exista la asimetría de edad necesaria para definir el caso como abuso, bajo la presunción de que el mismo existe cualquiera que sean las circunstancias en las que se ha producido un contacto sexual ${ }^{81}$. Efectivamente el artículo 183 quáter excluye la responsabilidad penal "cuando el autor sea una persona próxima al menor por edad y grado de desarrollo o madurez". Con la presente previsión se incorpora, en este precepto, el contenido del artículo 8.1 de la Directiva de 13 de diciembre de 2011, que establece como condición que esta clase de actos no impliquen abusos, esto es, no supongan conductas constitutivas de delito, pese a ser consentidas por el menor. Desde un punto de vista general, las previsiones normativas del artículo 183 quáter implican una excepción a la presunción, en principio, iuris et de iure, de irrelevancia del consentimiento, que tendrá como consecuencia la necesidad de valorar las condiciones en que se ha prestado el mismo y la relación entre los sujetos para poder determinar si la conducta es constitutiva o no de abuso según los tipos delictivos previstos en el presente ámbito de tipificación ${ }^{82}$, y que, "[...] necesariamente tendrán que valorarse sobre la base del equilibrio existente en la pareja, atendiendo a las circunstancias legales, es decir, la edad y el espíritu y mentalidad de ambos, debiendo rechazarse los casos de desequilibrio relevantes y notorios desde el punto de vista objetivo, pero también subjetivamente

\footnotetext{
81 Tamarit Sumalla, “Delitos contra la indemnidad sexual de menores", p. 425.

82 Ibidem.
} 
cuando aquél pueda inferirse del contexto en el que tiene lugar la relación, lo que determina un cuidadoso examen de cada caso [...]" ${ }^{83}$.

En tercer lugar, según la Exposición de Motivos de la Ley Orgánica 1/2015, el propio “[...] Comité de la Organización de las Naciones Unidas sobre Derechos del Niño sugirió una reforma del Código penal español para elevar la edad del consentimiento sexual, adecuándose a las disposiciones de la Convención sobre los Derechos de la Infancia, y así mejorar la protección que España ofrecía a los menores, sobre todo en la lucha contra la prostitución infantil [...]". ${ }^{84}$ En efecto, por lo que al Comité de Derechos Humanos del Niño respecta, en las Observaciones finales realizadas, en octubre de 2007, al informe presentado por España respecto al Protocolo Facultativo de la Convención sobre los Derechos del Niño relativo a la venta de niños, la prostitución infantil y la utilización de niños en la pornografía, dicho órgano sugiere una elevación de la edad del consentimiento sexual que, hasta ese momento, se ubicaba en los 13 años. Ahora bien, tal y como específicamente se recoge en la observación final número 24, el mencionado Comité “[...] recomienda que el Estado Parte considere la posibilidad de elevar la edad de consentimiento sexual para brindar una mayor protección contra los delitos abarcados por el Protocolo Facultativo", esto es, los delitos ubicados en el ámbito de la venta de niños, la prostitución infantil, así como la utilización de niños en la pornografía.

Este es precisamente el argumento que permite avalar la elevación de la edad del/de la menor víctima en el ámbito de los delitos de prostitución y pornografía infantil, en los que se observa una intervención punitiva reforzada en los supuestos en los que el sujeto pasivo sea menor de 16 años. En efecto, tanto el artículo 188.1 in fine, como el $189.2 \mathrm{CP}$ contemplan una respuesta cualificada, cuando de una víctima menor de 16 años se trate, en la medida en que la conducta cometida implica un mayor desvalor de acción, una mayor peligrosidad para el bien jurídico protegido, puesto que se presume iuris et de iure que los menores de 16 años se encuentran en situación de vulnerabilidad ${ }^{85}$. Se trata, por lo tanto, en el sentido ahora apuntado, de dar una respuesta a las recomendaciones que en el año 2007 el Comité de Derechos del niño realizó al Estado Español, sugiriendo una elevación de la edad del consentimiento sexual, para brindar una mayor protección contra los delitos abarcados

83 Así lo prevé el Tribunal Supremo en el Fundamento Jurídico segundo de la Sentencia1001/2016, de 18 de enero.

84 En opinión de Gómez Tomillo, “Capítulo II Bis. De los abusos y agresiones sexuales a menores de dieciséis años”, p. 518, este incremento de edad, de alguna manera, se ve compensado con la apertura de la posibilidad de que los menores de 16 años mantengan relaciones sexuales consentidas con una persona "próxima al menor por edad y grado de desarrollo y madurez" (art. 184 quater).

85 Góméz Tomillo, "Capítulo V. De los delitos relativos a la prostitución y a la explotación de menores”, p. 597. 
por el Protocolo Facultativo de la Convención sobre los Derechos del Niño relativo a la venta de niños, la prostitución infantil y la utilización de niños en la pornografía.

Ahora bien, volviendo a la fijación de la edad del consentimiento sexual, en general, en el límite de los 16 años, contrariamente a lo que hace el legislador de 2015, lejos de centrar la atención en aquellas modalidades delictivas en las que pone el foco el Protocolo de 2007 (venta, prostitución y pornografía infantil) extiende la elevación de la edad del consentimiento sexual también a los delitos contra la indemnidad sexual de los menores (abusos y agresiones sexuales), no sólo con las problemáticas que genera, tal y como hemos evidenciado, sino fundamentalmente respecto de la necesidad de atender, en la concreta protección generada en el ámbito del "Ius Puniendi" de los menores de edad, a las aportaciones que en torno a la vulnerabilidad subjetiva y situacional hemos visto en el ámbito de la Victimología evolutiva.

Es más, frente a las observaciones realizadas por el Comité de $\mathrm{Na}$ ciones Unidas al informe presentado por España en el año 2007 que, en el sentido apuntado, parece centrar la atención en los delitos de trata, prostitución y pornografía infantil, la anterior edad del consentimiento sexual, ubicada en los 13 años, tenía una perfecta fundamentación sobre la base de la ya mencionada Decisión Marco 2004/68/JAI, del Consejo, de 22 de diciembre de 2003, relativa a la lucha contra la explotación sexual de los niños y la pornografía infantil que, en el sentido ya apuntado, preveía una especial protección para los niños que " [...] no hubieran alcanzado la edad del consentimiento sexual según el Derecho Nacional [...]", que no remitía a la totalidad de menores de 18 años (a pesar de la delimitación del ámbito de aplicación subjetivo de la Decisión-Marco de 2004) y que respondía, a nuestro modo de ver, muy adecuadamente, al modelo de presunción iuris et de iure de incapacidad de los menores de 13 años para prestar un consentimiento válido en lo referente a la vida sexual ${ }^{86}$.

En efecto, la tutela penal reforzada de los menores víctimas de delitos de naturaleza sexual, a excepción de los promulgados por el Comité de Derechos del niño (trata, prostitución y pornografía infantil), debería pivotar sobre la existencia de una especial necesidad de protección sustentada sobre la base de una vulnerabilidad subjetiva, vinculada a la falta de madurez y de desarrollo físico y psíquico, y de una vulnerabilidad situacional que ubique a dichos menores en un ámbito de subordinación del que se prevale el sujeto activo. Así lo ha venido manifestando el Tribunal

86 En contra de este planteamiento, Molina BlázQuez, "Los menores y la legislación penal”, p. 483, que considera que la elevación de la edad del consentimiento sexual a los 16 años resulta adecuada y coherente con el resto del Ordenamiento jurídico, que sitúa en esa edad el límite para la emancipación, para la integración en el mercado laboral y para el consentimiento sanitario. 
Supremo cuando en relación a los comportamientos de naturaleza sexual con menores de 13 años, justificaba dicho límite cronológico de edad "[...] en la imposibilidad que tenían los niños, dada su escasa edad, de oponerse a sus designios, lo que implica un plus respecto a la vulnerabilidad del menor de 13 años, [...] situación de vulnerabilidad en el proceso de maduración y formación de la personalidad, puesto que no se ha alcanzado un nivel de desarrollo mental ni físico que permita controlar u oponerse a la involucración en un contexto sexual [...]" 87 .

Es cierto que el principio de legalidad, de seguridad jurídica y de taxatividad obligan, en estos casos, como en otros muchos, a objetivar una serie de criterios que, en su mayoría, sólo pueden garantizarse sobre la base de la existencia del dato cronológico de la edad. Ahora bien, la previsión de un límite taxativo de edad en el que se ubique la internacionalmente conocida como "edad del consentimiento sexual", ni tiene que ser necesariamente el mismo para la totalidad de los delitos que afectan a la libertad/indemnidad de los menores de edad, basta que se garantice una tutela penal reforzada frente a las conductas que impliquen un mayor desvalor de acción, ni necesariamente ha de ubicarse en los 16 años, puesto que, ni los instrumentos internacionales vienen exigiéndolo, ni las aportaciones victimológicas parece que aconsejen dicho límite, y en última instancia, el límite de los 16 años, genera una antinomia jurídica entre el límite de la edad penal y el de la edad sexual, el primero ubicado en los 14 años (presunción de grado de madurez y de desarrollo para comprender la ilicitud de los actos cometidos) y el segundo en los 16, de difícil comprensión.

En última instancia, como destaca el propio Tribunal Supremo, la reforma operada por la LO 1/2015, de 30 de marzo, que suprime la referencia a la tutela de la indemnidad sexual del menor, responde exclusivamente a un prurito doctrinal del sector responsable de la redacción de la reforma, sesgo doctrinal que lamentablemente se aprecia en muchos otros preceptos de la reforma. Pero esta modificación no afecta al ámbito de comportamientos prohibidos que siguen siendo los mismos, pues cualquier abuso sexual puede ser calificado como "acto que atente a la indemnidad sexual de un menor" (redacción anterior), o como "acto de carácter sexual” (redacción actual), aunque es cierto que el cambio sí afecta a la configuración del bien jurídico protegido tal y como se había definido por esta Sala, reduce innecesariamente la calidad técnica del precepto y retoma un tono moralizante, que se había superado en la redacción anteriormente vigente ${ }^{88}$.

87 Véase el Fundamento Jurídico noveno de la Sentencia 398/2015, del Tribunal Supremo de 17 de junio.

88 Véase el Fundamento Jurídico décimo segundo de la Sentencia STS 652/2015 del Tribunal Supremo, de 3 de noviembre. En idéntico sentido, téngase en cuenta la Sentencia301/2016, de 12 de abril, del Tribunal Supremo. 


\section{A modo de conlusión. La tutela penal reforzada del/ de la menor víctima en el código penal: de un derecho penal moralizante hacia un derecho penal basado en el paradigma de la victimología evolutiva y la vulnerabilidad del menor de edad}

En el sentido mencionado hasta ahora, existen argumentos victimológicos que recomiendan la configuración de tipos penales cualificados cuando el/la menor víctima de los mismos se encuentra, en el sentido apuntado, en una situación de vulnerabilidad subjetiva o situacional de la que se prevale el sujeto activo, generando un mayor desvalor de acción que justifica una intervención punitiva de mayor intensidad. La vulnerabilidad subjetiva, asociada a características biológicas y psicosociales que generan situaciones de indefensión y de inferioridad, requiere, por lo tanto, de una mayor intervención respecto de aquellos colectivos de menores de edad que cronológicamente podemos llegar a considerar especialmente vulnerables, que son los ubicados, según las distintas aportaciones victimológicas, en el período de la infancia hasta los 12-13 años.

Ahora bien, junto a las aportaciones victimológicas, desde la perspectiva de la normativa internacional protectora de los menores víctimas de delitos, se incide en la necesidad no sólo de intervenir penalmente, desde un punto de vista general, cuando la víctima sea un menor de 18 años, sino especialmente, cuando el menor víctima no haya alcanzado la "edad mínima de consentimiento" que, se vincula al límite cronológico de edad en el que el menor no ha alcanzado el grado de madurez y de desarrollo físico y psicológico.

En efecto, por lo que respecta a las obligaciones internacionales derivadas de los instrumentos mencionados en este trabajo, la intervención jurídico-penal frente a supuestos de victimización de menores de edad, se condiciona, en algunas ocasiones, a la situación de especial vulnerabilidad en la que se encuentran algunos de estos menores y, en otras, a la denominada "edad de consentimiento sexual".

En relación a la primera de las condiciones, esto es la situación de especial vulnerabilidad en la que se encuentran los y las menores víctimas, los instrumentos internacionales se refieren a la necesidad de intervenir en aquellos casos que generan una situación de indefensión en el menor de edad víctima de delitos, propios de la denominada "vulnerabilidad situacional”, esto es, supuestos en los que las víctimas son menores de edad especialmente vulnerables, por razón del sexo (en el caso de niñas), de la situación de dependencia o, de su falta de madurez y de desarrollo físico y/o psicológico de los mismos. En estos supuestos, el incremento de la respuesta punitiva pivota sobre la base del mayor desvalor de acción que en estas modalidades delictivas genera la situación de indefensión de la víctima sobre el sujeto activo. 
En segundo lugar, en relación, fundamentalmente, a las obligaciones internacionales orientadas a la incriminación de las conductas de naturaleza sexual, la intervención del "Ius Puniendi" de cada uno de los Estados Parte, está condicionada por la denominada "edad del consentimiento sexual" del/de la menor víctima. En efecto, en el sentido ya manifestado los instrumentos internacionales que se ocupan de la incriminación de las conductas de naturaleza sexual en las que se involucra a menores de edad, contemplan respuestas punitivas diferentes a tenor de que el/la menor víctima haya o no alcanzado la denominada "edad del consentimiento sexual", fijada por cada Estado Parte. A mayor abundamiento, los instrumentos internacionales ahora mencionados, dejan discrecionalidad a los Estados para proceder a la delimitación de lo que viene concibiéndose como "edad del consentimiento sexual", entendida esta como el límite cronológico de edad a partir de la que cada Estado Parte presupone la concurrencia en el menor de edad, de un grado de madurez y de desarrollo que le permite adoptar decisiones de naturaleza sexual. Este límite cronológico de edad, desde el punto de vista del Ordenamiento Jurídico interno de cada Estado, fija la delimitación entre las conductas sexuales consentidas y aquellas que requerirán de una intervención penal.

Sin obviar que el límite de "edad del consentimiento sexual" (pivota sobre la falta de madurez y de desarrollo físico y psicológico), sitúa a los menores víctimas en una situación de indefensión de la que se prevale el sujeto activo, comportando un mayor desvalor de acción y, precisando, por lo tanto, de una respuesta punitiva cualificada, el legislador español ubica dicho dato cronológico de edad en los 16 años, sin atender, a nuestro modo de ver, al paradigma de la Victimología del desarrollo o evolutiva que aconseja un límite inferior por las razones que a continuación se mencionan.

En primer lugar, porque si dicho límite de edad ha de estar condicionado por el grado de madurez y de desarrollo del menor que le permita, en última instancia, adoptar decisiones en el ámbito de comportamientos de naturaleza sexual, desde una perspectiva general, son muchas las razones que apuntan a que dicho límite debe situarse en torno a los 13 años. Desde el punto de vista interno, además de la tradición jurídica de ubicar dicho límite en los 13 años (a pesar de la modificación incorporada con la Ley Orgánica 1/2015), no debemos olvidar que el límite para responder penalmente por la comisión de hechos delictivos (incluidos los de naturaleza sexual) se ubica en los 14 años. Este dato cronológico de la edad de 14 años debería servir para entender que a partir de dicha edad se dispone de un grado de madurez y de desarrollo físico y psicológico no limitado a la comprensión de la ilicitud de los hechos cometidos, sino extensible, igualmente, a otras facetas de la vida, incluida la sexual.

En segundo lugar, tal y como hemos venido destacando, contrariamente a las disposiciones derivadas de la Exposición de motivos de la 
Ley Orgánica 1/2015, las recomendaciones internacionales orientadas a la elevación del límite de edad del consentimiento sexual que, con anterioridad a la reforma, se ubicaba en los 13 años, se referían a determinadas modalidades delictivas, no extensibles, a priori, a la totalidad de los tipos delictivos ubicados en el ámbito de los comportamientos de naturaleza sexual. En efecto, ya hemos aclarado que el Comité de Derechos del niño de Naciones Unidas se refería a la necesidad de elevar la edad del consentimiento sexual en relación a los delitos de trata, prostitución y pornografía infantil, con la finalidad de dotar a los menores de una tutela global, frente a conductas, cuyo consentimiento carece de toda lógica jurídico-penal.

En tercer lugar, es cierto que el principio de legalidad, de seguridad jurídica y de taxatividad obligan, en estos casos, como en otros muchos, a objetivar una serie de criterios que, en su mayoría, sólo pueden garantizarse sobre la base de la existencia del dato cronológico de la edad. Ahora bien, la previsión de un límite taxativo de edad en el que se ubique la internacionalmente conocida como "edad del consentimiento sexual", ni tiene que ser necesariamente el mismo para la totalidad de los delitos que afectan a la libertad/indemnidad de los menores de edad, basta que se garantice una tutela penal reforzada frente a las conductas que impliquen un mayor desvalor de acción, ni necesariamente ha de ubicarse en los 16 años, puesto que, ni los instrumentos internacionales vienen exigiéndolo, ni las aportaciones victimológicas parece que lo aconsejen.

En efecto, la vulnerabilidad subjetiva, asociada a características biológicas y psicosociales que generan situaciones de indefensión y de inferioridad, requiere de una mayor intervención respecto de aquellos colectivos de menores de edad que cronológicamente podemos llegar a considerar especialmente vulnerables, que son los ubicados en la período de la infancia, esto es, hasta los 12-13 años; etapa en la que, según la Victimología del desarrollo, por un lado, presentan una mayor riesgo de victimización por la situación de dependencia del menor, así como por su escaso nivel de desarrollo físico, psicológico y social y, por otro, los supuestos de victimización pueden llegar a generar en los/as menores graves secuelas y trastornos psicopatológicos que podrían incluso acontecer en la etapa adulta, cuando los factores de protección del mismo resultaran insuficientes.

Desde esta perspectiva, si bien se admite como colectivo vulnerable a la totalidad de menores de edad, es decir, sujetos menores de 18 años, el hecho de que los menores de 12-13 años presenten un mayor riesgo no sólo de victimización, sino de desarrollar secuelas psicopatológicas más graves que el resto de menores de edad, es decir, los situados en la franja de edad entre 14 y 17 años, requiere, de un abordaje más tuitivo de estos/ as primeros/as, en tanto que grupo de edad más vulnerable en el ámbito victimológico. 
En definitiva, las características individuales de los niños y niñas que les sitúan en una posición de especial vulnerabilidad frente al riesgo de ser victimizados/as, así como las posibles secuelas dimanadas de dichos procesos pueden llegar a condicionar su desarrollo evolutivo, justificando, no sólo un mayor abordaje victimológico, sino también un tratamiento jurídico-penal diferenciado en aquellas tipologías delictivas en las que la víctima sea un menor de edad especialmente vulnerable que, al albur de lo manifestado, hace referencia a los menores de 14 años.

Esta clase de victimizaciones traducidas a los tipos delictivos previstos en el ámbito del Código penal español requiere de la existencia de modalidades delictivas, por un lado, tipificadas sobre la base de la minoría de edad del sujeto pasivo, en cuanto que existen determinados bienes jurídicos que sólo deben protegerse respecto del menor de edad (como "child gromming", o el delito de exhibicionismo) y, por otro, de tipos penales cualificados con marcos punitivos agravados, con motivo de la especial vulnerabilidad del sujeto pasivo, esto es, la minoría de edad del mismo.

Es evidente, por lo tanto, que victimológicamente existen razones que justifican o bien una necesidad de respuesta punitiva, o bien una respuesta punitiva agravada, cuando el sujeto pasivo es un menor de edad, a la vista de los fundamentos victimológicos previstos, pero básicamente sobre la base de la especial vulnerabilidad subjetiva y situacional a las que nos acabamos de referir, debiendo destacarse la necesidad de una intervención especialmente protectora del colectivo de menores de edad que victimológicamente se considera como especialmente vulnerable, habida cuenta, de la edad y de la situación de dependencia en la que se encuentran, esto es, los y las menores hasta 12-13 años.

Así, si victimológicamente la situación de especial vulnerabilidad de los/las menores víctimas, se sitúa fundamentalmente, por debajo de los 13 años, la tutela penal reforzada también debería situarse en torno a dicho límite cronológico, tal y como venía sucediendo hasta la reforma del 2015. La opción del legislador español de elevar dicho límite de edad hasta los 16 años, ni encuentra fundamento jurídico internacional alguno, ni se sustenta sobre la base de los postulados de la vulnerabilidad subjetiva de los menores víctimas, de la que debería prevalerse el sujeto activo y, en última instancia, sólo parece responder, como muy acertadamente ha destacado el Tribunal Supremo, a un sesgo moralizante, muy alejado de los postulados tradicionales que fundamentan la intervención del ius Puniendi del Estado.

\section{Bibliografía}

Abad, J./Pereda, N./Guilera, G., "La exposición de los menores españoles a la violencia familiar", en Boletín Criminológico, núm. 131, noviembre 2011, pp. 1-4. 
Álvarez García, J. /Ventura Püchel, A., "Delitos contra la vida humana independiente: homicidio y asesinato (artículos 138, 139, 140 y 140bis)"”, en Comentario a la reforma de 2015, dirigido por Quintero Olivares. Edit. Thomson Reuters Aranzadi. Cizur Menor, pp. 313-332.

ANDREU FERnÁNDEZ, A., "Menores víctimas y situaciones de victimización”, en Archivos de Criminología, Seguridad Privada y Criminalística, 2016, pp. 56-74.

Bach Fabregó, R. /Gimeno Cubero, M.A., "Clases y contenido de penas y ejecución de las penas (arts. 33, 36, 39, 46, 50, 53, 56, 58, 66bis, 83, 100, 103 y 116 CP)", en La Reforma Penal de 2010: análisis y comentarios, dirigidos por Quintero Olivares. Edit. Thomson Reuters. Cizur Menor, 2010, pp. 71-90.

Blades Pacheco, J.A., "Caracterización victimológica ligada al proceso de denuncia en víctimas de abuso sexual infantil”, en SEC Ciencia, vol. 1, 2018, pp. 1-10.

Boldoma Pasamar, M.A., "Principales aspectos sustantivos del nuevo Derecho Penal Juvenil español”, en La ciencia del Derecho Penal ante el nuevo siglo. Libro homenaje al profesor Doctor Don José Cerezo Mir, edit. Por Díez Ripollés, Romeo Casabona, Gracia Martín e Higuera Guimerá. Edit. Tecnos. Madrid, 2002, pp. 1553-1574.

De Los Santos Farinati, F.A., "Consideraciones sobre el maltrato a la infancia”, en Infancia maltratada. Calidad y eficacia como metas. Edit. ADIMA. Sevilla, 1995, pp. 268-270.

Dolz Lago, M.J., La nueva responsabilidad penal del menor (Comentarios a la Ley Orgánica 5/2000, de 12 de enero). Edit. Tirant lo Blanch. Valencia, 2000.

Fiscalía General Del Estado, “Circular 4/2005, relativa a los criterios de aplicación de la Ley Orgánica de Medidas de Protección Integral contra la violencia de género".

FinKelHoR, D., "Factores de riesgo", en Violencia contra niños, coordinado por Sanmartín Espugles, Edit. Ariel. Barcelona, 2008, pp. 155-178.

Gamboa De Trejo, A., "Víctimas de la violencia”, en www.letrasjuridicas. com, 2004.

Gómez Tomillo, M., "Capítulo II bis. De los abusos y agresiones sexuales a menores de dieciséis años”, en Comentarios prácticos al Código penal. Tomo II. Los delitos contra las personas. Artículos 138-233, dirigidos por Gómez Tomillo. Edit. Thomson Reuters Aranzadi. Cizur Menor, 2015, pp. 517-538.

Gómez Tomillo, M., "Capítulo V. De los delitos relativos a la prostitución y a la explotación de menores", en Comentarios prácticos al Código penal. Tomo II. Los delitos contra las personas. Artículos 138-233, dirigidos por Gómez Tomillo. Edit. Thomson Reuters Aranzadi. Cizur Menor, 2015, pp. 567-574. 
GonzÁlez Agudelo, G., "El menor como víctima del delito", en Menores. Responsabilidad penal y atención psicosocial, coordinado por Ruíz Rodríguez y Navarro Guzmán. Edit. Tirant lo Blanch. Valencia, 2004, pp. 269-300.

Gracia Fúster, E., Las víctimas invisibles de la violencia familiar. El extraño iceberg de la violencia doméstica. Edit. Paidós. Barcelona, 2002.

Gutierrez Castañeda, A., "Penas privativas de derechos”, en Comentarios a la Reforma penal de 2010. Edit. Tirant lo Blanch. Valencia, 2010, pp. 101-106.

Herrera Moreno, M., La hora de la víctima. Compendio de Victimología. Edit. Edersa. Madrid, 1996.

Higuera Guimerá, J.F., Derecho Penal juvenil. Edit. Bosch. Barcelona, 2003.

LANDrove DíAz, G., La moderna Victimología. Edit. Tirant lo Blanch. Valencia, 1998.

MARTín LóPEz, T., "Delincuencia juvenil y normativa internacional”, en Homenaje al Dr. Marino Barbero Santos. In Memoriam, vol. I, coordinado por Nieto Martín. Edit. Universidad de Salamanca. Cuenca, 2001, pp. 329-352.

Martínez Roig, A., "Factores de vulnerabilidad infantil para el maltrato y abandono", en Los malos tratos y el abandono infantil, dirigido por de Paul Ochotorena. Edit. Universidad del País Vasco/Euskal Herriko Unibertsitatea, 1988, pp. 73-84.

Molina BlázQuez, C., "Los menores y la legislación penal: el menor víctima y el menor infractor", en Tratado del menor. Protección jurídica a la infancia y a la adolescencia, coordinado por Martínez García. Edit. Thomson Reuters Aranzadi. Cizur Menor, 2016, pp. 463-558.

Morillas Fernández, D./Patró Hernández, R.M/ Aguilar Cárceles, M.M., Victimología: un estudio sobre la víctima y los procesos de victimización. Edit. Dykinson. Madrid, 2011.

Ornosa Fernández, M.R., Derecho Penal de menores. Comentarios a la Ley Orgánica 5/2000, de 12 de enero, reguladora de la responsabilidad penal de los menores. Edit. Bosch. Barcelona, 2001.

OtTnehof, R., "La responsabilidad penal de los menores en el orden interno e internacional", en Revista Internacional de Derecho Penal, vol. 75, 2004, pp. 1-26.

Pereda, N., "Revisión sistemática de las consecuencias psicológicas en menores víctimas de terrorismo", en Revista española de investigación criminológica, 2011, pp. 1-28.

Pereda, N., "Menores víctimas de terrorismo: Una aproximación desde la Victimología del desarrollo”, en Anuario de Psicología Jurídica, vol. 22, 2012, pp. 13-24. 
Pereda, N./ABAD, J./Guilera, G., "Victimología del desarrollo. Incidencia y repercusiones de la victimización y la polivictimización en jóvenes catalanes", en Invesbreu, núm. 55, 2012, pp. 2-4.

Pereda, N./AbAd, J./Guilera, G., Victimología del desarrollo. Incidencia y repercusiones de la victimización y la polivictimización en jóvenes catalanes. Edit. Centre d'Estudis Jurídics i Formació Especiatzada. Barcelona, 2012.

Pereda, N./GuIlera, G./ABAD, J., "Victimización infanto-juvenil en España: una revisión sistemática de estudios epidemiológicos", en Papeles del psicólogo, vol 35, 2014, pp. 66-77.

PÉREZ MACHÍo, A.I., El tratamiento jurídico-penal de los menores infractores -LO8/2006- (Aspectos de Derecho comparado y especial consideración al menor infractor inmigrante). Edit. Tirant lo Blanch. Valencia, 2007.

Pinto Cortez, C./ Venegas Sanhueza, K., "Experiencias de victimización y polivictimización en jóvenes chilenos”, en Señales, núm. 14, 2015, pp. 5-25.

Puyol Wilson, C. /Salinas Chaud, M.I., "Agresiones sexuales infanto-juveniles: una aproximación a víctimas de agresores menores de edad”, en Salud y Sociedad, vol. 4, núm.3, 2013, pp. 266-282.

SÁNChez García DE PAz, I., "La nueva ley reguladora de la responsabilidad penal del menor", en Actualidad Penal, vol. 3, 2000, pp. 699-727.

Sanz Hermida, A.M., Victimas de delitos: derechos, protección y asistencia. Edit. Iustel. Madrid, 2009.

TAmarit Sumalla, J.M., "Los delitos sexuales. Abusos sexuales. Delitos contra menores (arts. 178, 180, 181, 183, 183 bis)", en La Reforma penal de 2010: análisis y comentarios, dirigido por Quintero Olivares. Thomson Reuters. Cizur Menor, 2010, pp. 165-172.

VÁzquez González, C., Delincuencia juvenil. Consideraciones penales y criminológicas. Edit. Colex, Madrid, 2003. 